\title{
GRUPO ITARARÉ NA REGIÃO DE ITU, ESTADO DE SÃO PAULO: INTENSOS PROCESSOS GLACIAIS EROSIVOS E DEPOSICIONAIS
}

Setembrino PETRI

Annabel PEREZ-AGUILAR

Artur CHAHUD

Sibele EZAKI

Ana Maria GÓES

Silvio Takashi HIRUMA

Paulo Alves de SOUZA

\begin{abstract}
RESUMO
O Grupo Itararé, Neopaleozoico da Bacia do Paraná, está exposto em grande parte da faixa leste do Estado de São Paulo, predominantemente sobre rochas pré-cambrianas. As áreas aqui designadas Itu e Salto são notáveis pela abundância de registros glaciais, embora de natureza distinta. Este trabalho discute as feições glaciais presentes nessas áreas como subsídio para reconstruções paleoambientais, partindo-se de estudos prévios, e traz observações inéditas de uma frente sedimentar exposta, por escavação, na Pedreira Colonial. Na área-Salto, o destaque são as evidências de forte ação erosiva glacial, tais como, rochas moutonnées, só encontradas no Brasil nessa região, e pavimentos estriados, associados a tilitos, diamictitos e depósitos aquoso-glaciais que atingem até $20 \mathrm{~m}$ de espessura. Na área-Itu, destacam-se os espessos depósitos aquoso-glaciais e, subordinadamente, diamictitos e tilitos que podem alcançar até $300 \mathrm{~m}$ de espessura.
\end{abstract}

Palavras-chave: Grupo Itararé; Glacial; Tilitos; Diamictitos; Pedreira Colonial; Rocha moutonnée; Pavimento estriado.

\section{ABSTRACT}

THE ITARARÉ GROUP IN THE REGION OF ITU, STATE OF SÃO PAULO: INTENSE GLACIAL EROSIONALAND DEPOSITIONAL PROCESSES. The Itararé Group, Neopaleozoic of the Paraná Basin, is exposed in a large area of the eastern part of State of São Paulo, predominantly overlying Precambrian rocks. Although of distinctive nature, the areas named here Itu and Salto, are notable for the abundance of glacial records. As a contribution to paleoenvironmental reconstructions, this paper analyzes the glacial features present in these areas, starting from previous studies and including new observations of a sedimentary front exposed in the Colonial Quarry. The Salto area stands out for the evidences of strong glacial erosive action, such as roches moutonnées, which are only found in this region in Brazil, and striated pavements, associated with tillites, diamictites and glacial aqueous deposits that reach up to $20 \mathrm{~m}$ in thickness. Contrastingly, thick glacial aqueous deposits reaching $300 \mathrm{~m}$ in thickness stand out in the Itu area, with subordinate tillites and diamictites.

Keywords: Itararé Group; Glacial; Tillites; Diamictites; Colonial Quarry; Roche moutonnée; Striated pavement. 


\section{INTRODUÇÃO}

Depósitos sedimentares relacionados ao resfriamento global durante o Mississippiano até o Pennsylvaniano, podendo eventualmente chegar ao Asseliano (LPIA - Late Paleozoic Ice Age), são conhecidos, praticamente, em todas as bacias do Gondwana, conforme sintetizado em FIELDING et al. (2008), LOPÉZ-GAMUNDI \& BUATOIS (2010), ISBELL et al. (2012) e LIMARINO et al. (2014). Na Bacia do Paraná, são representados pelo Grupo Itararé, que compõe a base da Supersequência Gondwana I de MILANI (1997) e MILANI \& RAMOS (1998).

A distribuição geográfica dos depósitos do Itararé é condicionada a reativações de lineamentos neoproterozoicos (cf. FRANÇA \& POTTER 1991). Os depósitos de maior espessura e antiguidade estão distribuídos no setor norte/nordeste da bacia, estados de São Paulo e Paraná, enquanto ao sul, nos estados de Santa Catarina e Rio Grande do Sul, as espessuras diminuem (SCHNEIDER et al. 1974, MILANI et al. 2007, HOLZ et al. 2010).

Uma das características marcantes do Grupo Itararé é a heterogeneidade de fácies, incluindo diversas litologias, com destaque aos tilitos, diamictitos, arenitos, siltitos, folhelhos e ritmitos; subordinadamente ocorrem camadas de carvões e carbonatos (ROCHA-CAMPOS 1967, SCHNEIDER et al. 1974). Tal variedade litofaciológica é resultado dos múltiplos processos de avanço e retração de lobos glaciais, em paleoambientes continentais a marinhos (SANTOS et al. 1996, VESELY et al. 2015, MOTTIN et al. 2018). Maiores detalhamentos sobre o significado das associações de fácies no contexto da estratigrafia de sequência foram oferecidos por outros autores (VESELY \& ASSINE 2004, 2006; CASTRO et al. 2005).

Desde o início do século XX, são conhecidas tentativas de divisão litoestratigráfica para 0 Grupo Itararé, com destaque para SCHNEIDER et al. (1974), nos estados do Paraná e Santa Catarina, e FRANÇA \& POTTER $(1988,1991)$, para toda a porção brasileira da bacia. Estes últimos autores, a partir da análise em subsuperfície de testemunhos de sondagem, identificaram no Estado de São Paulo os estratos mais antigos do Grupo Itararé (Formação Lagoa Azul), bem como suas maiores espessuras, que atingem $1.556 \mathrm{~m}$ na sondagem 2-LA-1-SP, em Oswaldo Cruz - SP. Contudo, são verificadas dificuldades no entendimento das relações e correlações estratigráficas entre dados de superfície e de subsuperfície, em função de intem- perismo e variação lateral de fácies e paleoambientes. A síntese dessas e de outras contribuições foi materializada nas cartas estratigráficas mais recentes disponíveis para a Supersequência Gondwana I, publicadas por MILANI et al. (2007) e HOLZ et al. (2010), incluindo os dados bioestratigráficos mais robustos, advindos de macrofósseis vegetais, invertebrados e palinomorfos.

Palinozonas são comumente utilizadas para correlações a longas distâncias de distintas bacias do Gondwana. Para o Itararé, foram definidas três palinozonas, da base para o topo, Zona Ahrensisporites cristatus, Zona Crucisaccites monoletus e Zona Vittatina costabilis. Esta última reconhecida no topo do Itararé e também ocorrente praticamente em toda a Formação Rio Bonito (SOUZA \& MARQUES-TOIGO 2005, SOUZA 2006). Diversas datações radiométricas foram obtidas nas unidades da Supersequência Gondwana I (vide síntese em CAGLIARI et al. 2016, GRIFFIS et al. 2018, ROCHA-CAMPOS et al. 2019). Embora haja necessidade de contínua produção de dados, as datações modernas colocam idade permiana basal para a Formação Rio Bonito (unidade sobrejacente ao Itararé), e carbonífera para o Grupo Itararé, o que requer reavaliações sobre o significado da duração dos eventos glacial e de deglaciação na Bacia do Paraná, bem como das unidades bioestratigráficas relacionadas.

Esta contribuição enfoca depósitos sedimentares e feições erosivas ocorrentes na região de Salto e Itu, Estado de São Paulo (Figura 1), situada no limite entre o altiplano cristalino pré-cambriano e a Depressão Periférica, onde os estratos fanerozoicos mergulham para NNW. A comparação das áreas de Salto e Itu, sob o ponto de vista de suas respostas às ações glaciais, constitui o objetivo deste trabalho. Ressalta-se que as áreas, aqui denominadas área-Salto e área-Itu, contíguas do ponto de vista geográfico, possuem significado geológico, não se referindo ao perímetro urbano desses municípios. Os registros geológicos da Pedreira Colonial, situada na área-Itu, são apresentados de forma inédita nessa contribuição, assim como material fotográfico de outras ocorrências.

\section{REGISTROS GLACIAIS DE SALTO E ITU}

A região Salto-Itu (Figura 1) situa-se na transição entre os terrenos pré-cambrianos a leste do Estado de São Paulo e o início da sucessão fanerozoica da Bacia do Paraná, cujos estratos mergulham para NW. Do ponto de vista geomorfológico, 

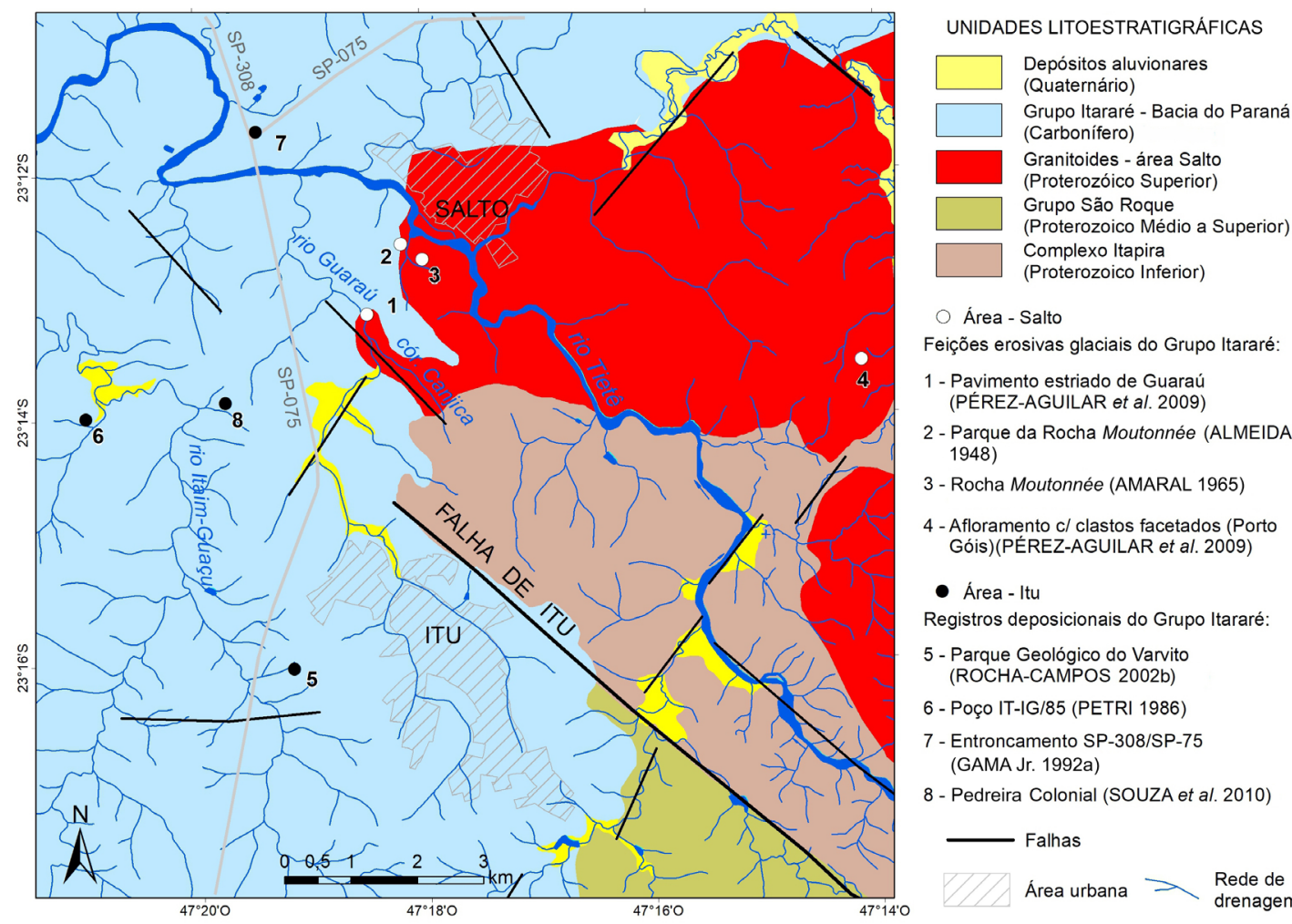

Área - Salto

Feições erosivas glaciais do Grupo Itararé:

1 - Pavimento estriado de Guaraú (PÉREZ-AGUILAR et al. 2009)

2 - Parque da Rocha Moutonnée (ALMEIDA 1948)

3 - Rocha Moutonnée (AMARAL 1965)

4 - Afloramento c/ clastos facetados (Porto Góis)(PÉREZ-AGUILAR et al. 2009)

- Área - Itu

Registros deposicionais do Grupo Itararé:

5 - Parque Geológico do Varvito (ROCHA-CAMPOS 2002b)

6 - Poço IT-IG/85 (PETRI 1986)

7 - Entroncamento SP-308/SP-75 (GAMA Jr. 1992a)

8 - Pedreira Colonial (SOUZA et al. 2010)
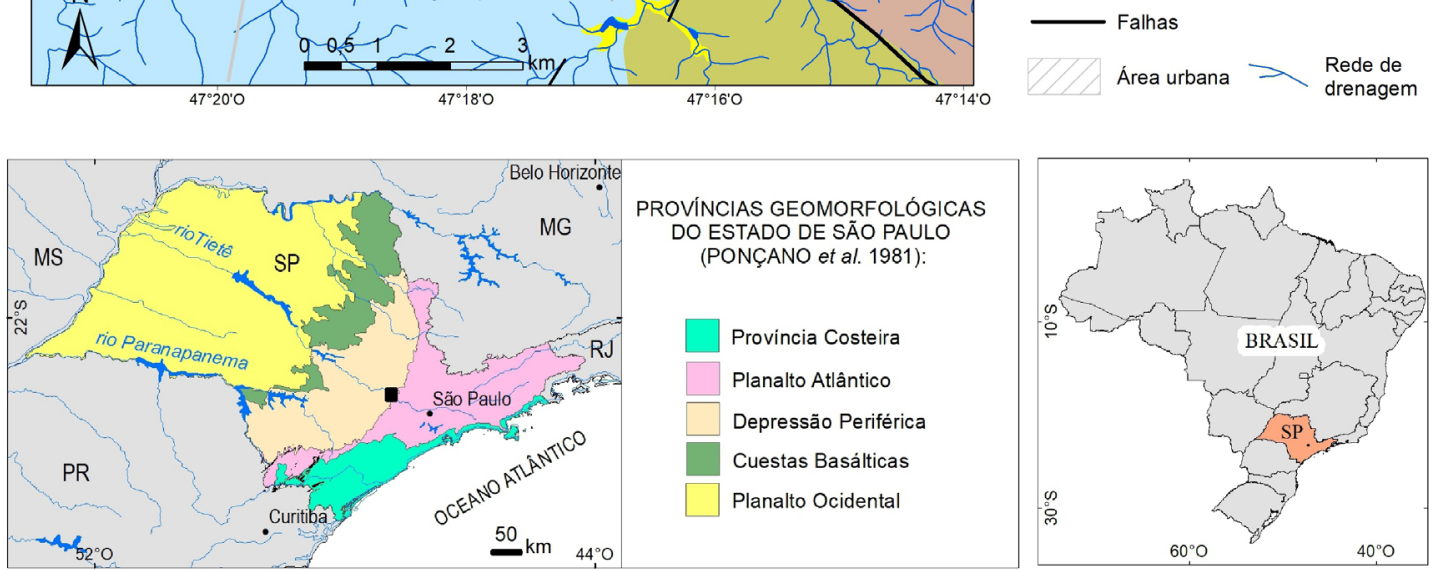

FIGURA 1 - Mapa geológico das áreas de Itu e Salto, Estado de São Paulo (Adaptado de MODENESI 1974a, b; TEIXEIRA et al. 1991; NEVES 2005), indicando os locais das principais feições glaciais do Grupo Itararé. Abaixo, inserção da área (quadrado preto) nas províncias geomorfológicas do Estado de São Paulo (PONÇANO et al. 1981).

a região situa-se na transição entre as províncias geomorfológicas do Planalto Atlântico e Depressão Periférica (ALMEIDA 2018). Salto e Itu se diferenciam pelas respostas aos impactos da glaciação do Itararé. Em Salto, os depósitos aquoso-glaciais são de pequena espessura, excepcionalmente atingindo $20 \mathrm{~m}$, enquanto em Itu, chegam a $300 \mathrm{~m}$ (ODA 1998).

\section{1 Área-Salto}

A ação glacial do LPIA (Late Paleozoic Ice Age) em Salto ocorreu sobre granitoides
(Proterozoico Superior) intrusivos nas rochas metamórficas do Grupo São Roque (Proterozoico Médio a Superior) e Complexo Itapira (Proterozoico Inferior) (Figura 1).

A extensa área de afloramento desse granito, a partir do sul do sítio urbano de Salto, estende-se para leste e sudeste. Inclui-se na definição da área-Salto, os afloramentos de granito com ampla exposição de numerosos matacões e com escassa cobertura cenozoica. Só estes granitos reúnem condições para o desenvolvimento de rochas moutonnées, quando submetidos a fortíssima ação erosiva 
glacial. Os afloramentos que preenchem estas condições são os que se localizam ao sul do sítio urbano do município de Salto e sua continuação para o ribeirão Guaraú, onde ocorre um pavimento de granito estriado. A espessura de depósitos aquoso-glaciais nesses locais chega até $20 \mathrm{~m}$ (ALMEIDA 1948, PEREZ-AGUILAR et al. 2009).

Outros granitos, situados a leste e sudeste, estão sob a ação da Falha de Itu e de outras falhas mais a leste, formando brechas e milonitos, bem como separando porções de granito que não seriam ideais para formar esculturas por ação das geleiras. $\mathrm{Na}$ área dos granitos ocorre profundo entalhamento dos cursos de água, gerando vales estreitos com vertentes íngremes (MODENESI 1974b). Destacase o registro de grande número de formas de erosão subglacial que ocorre diretamente sobre o granito exposto, como é o caso do pavimento estriado de Guaraú, descrito por PEREZ-AGUILLAR et al. (2009) e a rocha moutonnée do afloramento clássico do Município de Salto (ALMEIDA 1948, ROCHA-CAMPOS 2002a).

MODENESI (1974a) distingue nas áreas cristalinas e sedimentares nas cercanias de Itu e Salto, níveis topográficos com altitudes decrescentes do Planalto Atlântico rumo à Depressão Periférica, em geral, com declividades (para NW) inferiores a $1 \%$. Tais níveis seccionam diferentes litologias e são separados por rampas ou degraus de declividade maior. Nos granitos, as maiores elevações correspondem aos topos aplainados da Serra de Itaguá $(950 \mathrm{~m})$ - superfície cimeira local, centro dispersor da drenagem. Destaca-se na região de Salto, remanescentes de uma superfície fóssil em exumação, denominada Itaguá por ALMEIDA (1959), anteriormente reconhecida por DE MARTONNE (1940) - superfície PréPermiana, também identificada por AB'SÁBER (1948). Conforme ALMEIDA (2018), essa superfície teria sido modelada nas rochas graníticas e quartzíticas da borda da Bacia do Paraná pela glaciação carbonífera - a rocha moutonnée de Salto, descrita à frente, testemunharia a sua esculturação pela ação do gelo.

Na planície fluvial, no trecho onde o ribeirão Guaraú recebe seu afluente córrego Canjica, aflora um granito caraterístico da área-Salto (Figura 1), onde PEREZ-AGUILLAR et al. (2009) descreveram o pavimento estriado de Guaraú (Figura 1 Ponto 1, Figura 2). O granito foi exposto a partir da erosão dos depósitos aquoso-glaciais pelo ribeirão Guaraú, possivelmente acentuada pela linha da falha. O talvegue do ribeirão Guaraú, que corre pa- ralelo à porção noroeste da Falha de Itu, está no limite entre o granito a leste e os depósitos aquoso-glaciais da área-Itu a oeste (Figura 1). O pavimento de granito estriado por atividades glaciais (Figuras 2A, 2B) foi exposto durante as atividades de olarias da Cerâmica Guaraú. Sobre o granito estriado, há depósitos glaciais (Figura 2C), representados por diamictitos maciços com frequentes blocos facetados e estriados - tilitos - intercalados com camadas de arenitos e siltitos com estratificações cruzadas e ritmitos com alternância de camadas claras de arenito muito fino e escuras de arenito relativamente mais grosso.

O Pavimento Estriado Guaraú dista $1 \mathrm{~km}$ do local da rocha moutonneé do parque de Salto
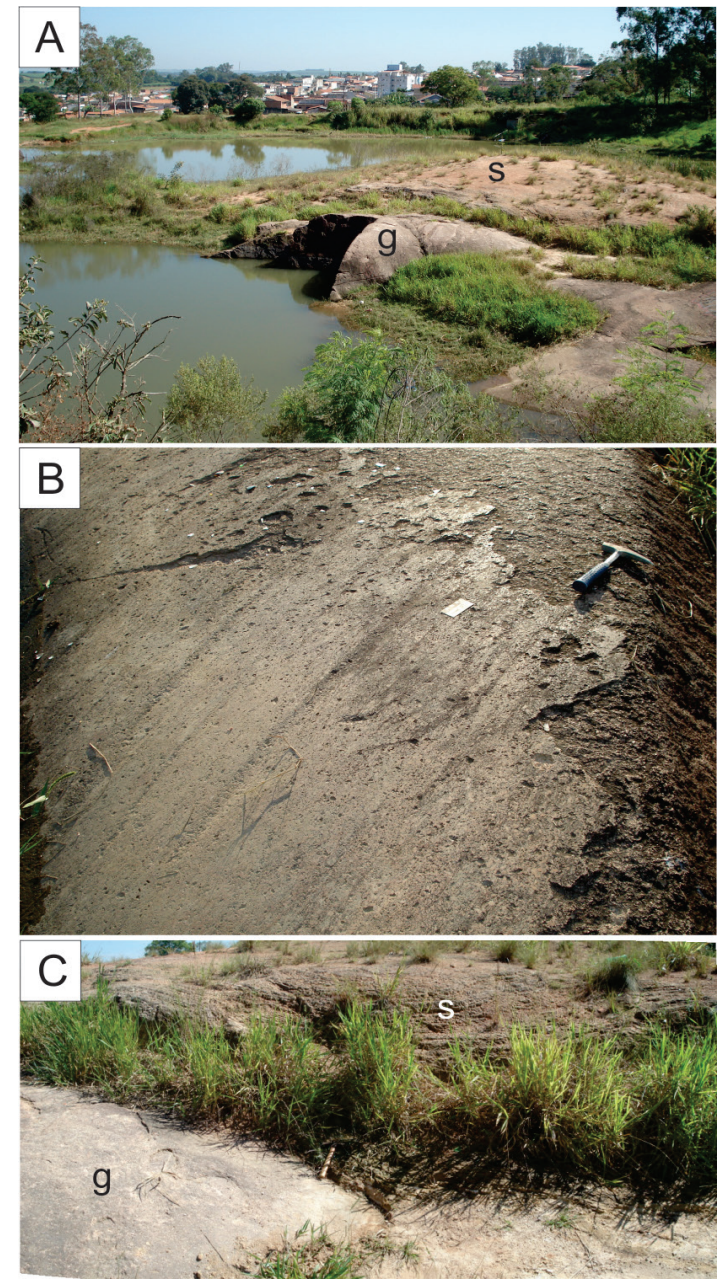

FIGURA 2 - (A) Pavimento Estriado Guaraú (g = granito estriado, $\mathrm{s}=$ sedimentos aquoso-glaciais) (Figura 1 - Ponto 1). (B) Ação erosiva do gelo sobre o granito com produção de estrias e sulcos, que indicam movimentação glacial para noroeste. (C) Sedimentos aquoso-glaciais de 2 a $3 \mathrm{~m}$ (s) de espessura acima do granito (g) (Fotografias realizadas no ano de 2007). 
(Figura 1 - Ponto 1, Figura 3A). Essa moutonnée, descoberta por Marger Gutmans do Instituto Agronômico de Campinas em 1946 e descrita por ALMEIDA (1948), constitui uma cúpula alongada com cerca de $20 \mathrm{~m}$ de comprimento e $3 \mathrm{~m}$ de altura (Figura 3B, 3C), cuja extremidade noroeste e face nordeste foram parcialmente destruídas pela lavra de granito; na superfície da extremidade sudeste ainda se observam estrias (Figura 3D) e sulcos orientados no sentido do deslocamento do gelo, de sudeste para noroeste. Quando o autor estudou essa ocorrência ela já estava em parte destruída, devido à exploração de blocos de granito para uso em revestimentos e calçamentos das cidades de Itu e Salto, entre outras finalidades. Graças aos esforços do Prof. Antonio Carlos Rocha-Campos da Universidade de São Paulo, a exploração foi interrompida para a criação do parque. ALMEIDA (1948) relatou ainda depósitos glaciais próximos ao longo de vales NW escavados em granito rosa do embasamento na área. A sudeste do Parque da Rocha Moutonnée, um diamictito de poucos metros de espessura cobre o granito com grande quan- tidade de seixos estriados e facetados, passando lateralmente a depósitos aquoso-glaciais de pequena espessura.

Uma segunda moutonnée, relatada por AMARAL (1965) (Figura 1 - Ponto 3), ocorre 340 $\mathrm{m}$ a sudeste da primeira, em um vale formado por um afluente do rio Tietê, no contato do embasamento pré-cambriano com tilitos do Grupo Itararé. Esta moutonné encontra-se em uma pequena depressão de direção E-W, coincidente com uma drenagem, subordinada a um vale glacial maior mencionado por ALMEIDA (1948), esculpido antes da deposição do tilito. Um bloco granítico maior apresenta superfícies esparsas com polimento, melhor preservadas nas partes íngremes, sem contudo apresentar assimetria. A $10 \mathrm{~m}$ desse, outro bloco apresenta estrias na face superior, com menos de $40 \mathrm{~cm}$ de comprimento. A direção das estrias varia de N35W a N60W, sugerindo terem sido geradas pela mesma ação glacial. $\mathrm{O}$ tilito ocorre por cerca de $30 \mathrm{~m}$ de extensão ao longo do corte da via férrea, acompanhando o pequeno córrego a sul da ocorrência, atingindo $8 \mathrm{~m}$ de espessura. $\mathrm{O}$ autor
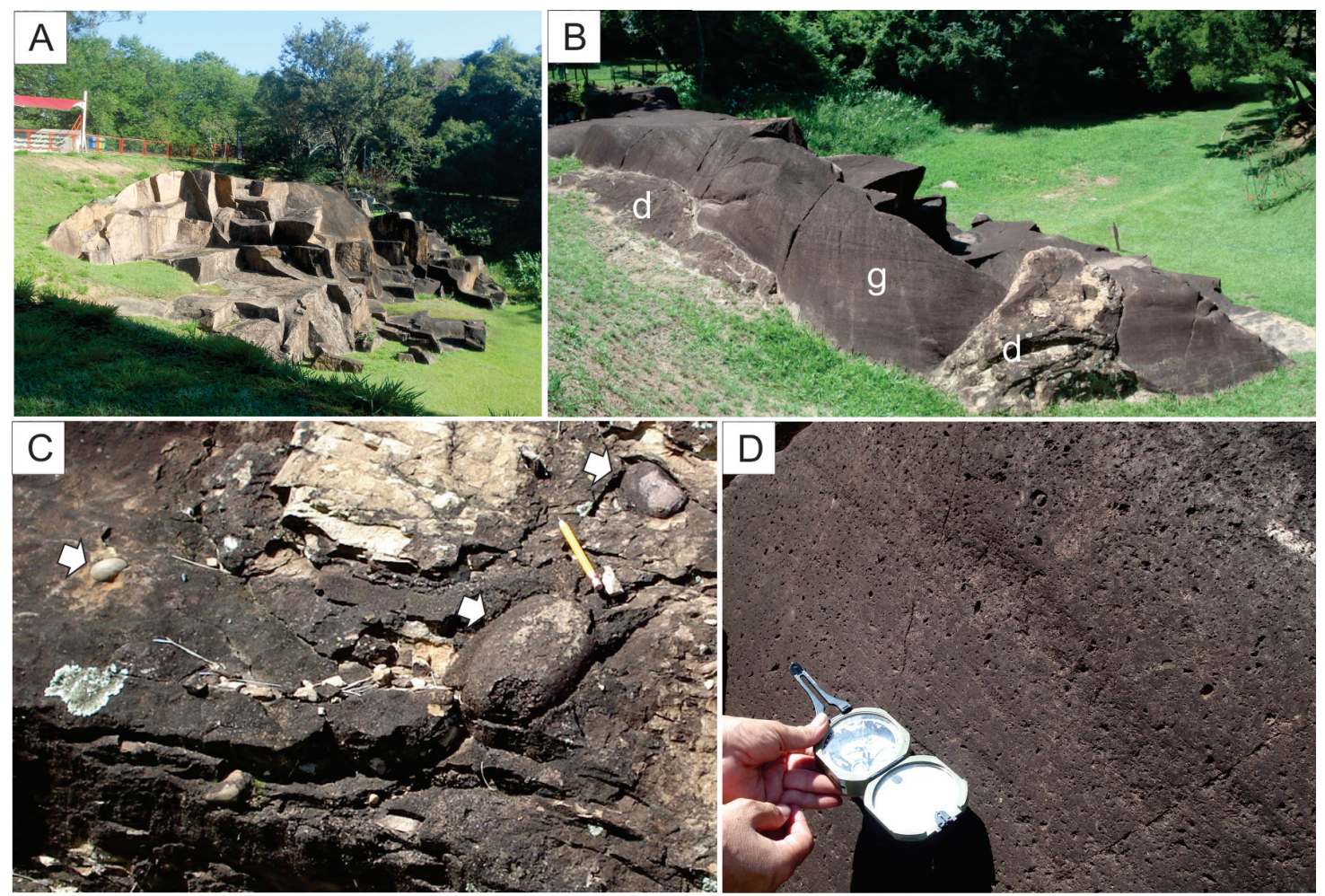

FIGURA 3 - (A) Parque da Rocha Moutonnée, em Salto. (B) Afloramento de granito (g) no Parque da Rocha Moutonnée, em Salto, evidenciando as estrias em sua superfície e diamictitos (d) a ele prensados e ainda preservados. (C) Detalhe do diamictito com clastos arredondados a subangulares, alguns facetados pela ação da geleira. (D) Estrias glaciais no granito (Ano 2007). 
considera que o tilito sofreu um retrabalhamento ocasionado pela lavagem de águas de degelo, em função da ocorrência de seixos com maior eixo paralelo a E-W.

VIVIANI \& ROCHA-CAMPOS (2002) investigaram o vale do rio Tietê, em torno da primeira moutonnée. Os autores relataram fortes marcas glaciais em grande número de granitos polidos com estriações. Tais exposições variam de 1-15 $\mathrm{m}$ de comprimento e 1-1,5 $\mathrm{m}$ de altura e se espalharam por pelo menos $1,2 \mathrm{~km}$. Na mesma área, ROCHA CAMPOS et al. (2008) reconheceram moutonnées menores e whalebacks; no leito do rio Tietê ocorrem outras estruturas como drumlins e eskeres. Essas observações, somadas àquelas de AMARAL (1965), evidenciam a grande extensão sob ação glacial na região de Salto.

Ainda na região de Salto, região da Fazenda Monte Belo (Porto Góis), ocorrem depósitos glaciais - cerca de $1 \mathrm{~m}$ - em meio a corpos graníticos. Destaque para clastos de quartzitos facetados e estriados e dispersos na matriz, interpretados por PEREZ-AGUILAR et al. (2009) como vestígios de um pavimento de clastos da geleira neopaleozoica (Figura 1 - Ponto 4, Figura 4).

\section{2 Área-Itu}

Define-se aqui como área-Itu, a região em que as espessuras de depósitos aquoso-glaciais são relativamente grandes, até $300 \mathrm{~m}$, segundo estimativa de ODA (1998). Esta área estende-se do sítio urbano da cidade, em todas as direções, até os afloramentos metamórficos pré-cambrianos, os quais afloram em consequência da Falha de Itu, de direção NW-SE, que passa imediatamente acima da cidade homônima (Figura 1). Conforme MODENESI (1974a), o relevo nessa área é caracterizado pela presença de colinas tabuliforrnes com vales em $\mathrm{V}$ aberto, apresentando vertentes convexas longas e de baixa declividade.

Destacam-se aqui como características da área-Itu: (i) a irregularidade topográfica do contato do embasamento pré-cambriano com os depósitos do Itararé; (ii) a maior espessura de seus depósitos aquoso-glaciais em relação à área-Salto; e, (iii) a maior diversificação litológica de seus depósitos com tendência a aumento de espessuras para oeste. Todas as características apontadas devem-se à posição da área-Itu no contato entre a região elevada do Pré-Cambriano a leste e o início dos depósitos fanerozoicos da Bacia do Paraná, mergulhando para NNW. A irregularidade topográfica do embasamento pré-cambriano pode ser visualizada por trabalhos de detalhes na área, tal como a contribuição de MEZZALIRA (1969).

Os depósitos aquoso-glaciais da área-Itu são de litologias variadas. Destacam-se os ritmitos constituídos de lâminas claras, mais espessas, de arenitos muito finos a siltitos, e escuras de siltitos e argilitos. Tais litologias chamaram a atenção de geólogos que visitaram a região (LEONARDOS 1938, MENDES 1944), resultando, em 1995, na

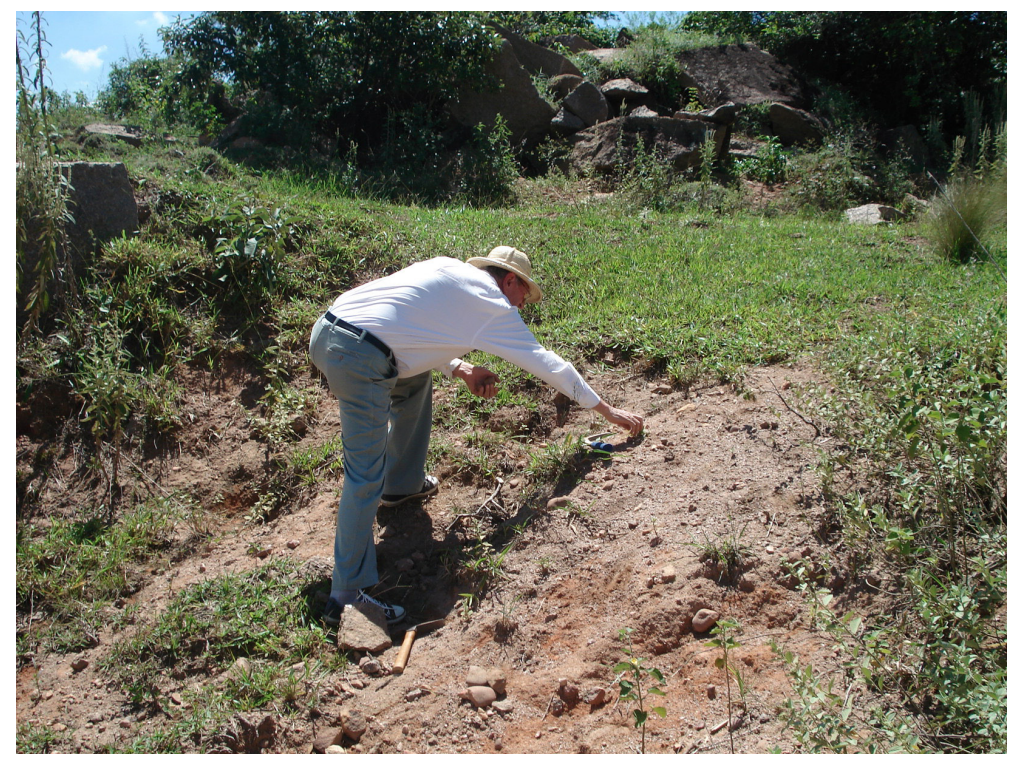

FIGURA 4 - Vista geral de depósitos glaciais com clastos imersos em matriz arenosa na Fazenda Monte Belo, Salto (Ano 2007). 
criação do Parque Geológico do Varvito (vide histórico em ROCHA-CAMPOS 2002b). Considerados originalmente varvitos, foram reconhecidos genericamente como ritmitos de folhelhos argilosos intercalados com arenitos muito finos a siltitos com clastos caídos, que se destacam pela forte laminação plano-paralela (Figura 1 - Ponto 5, Figura 5). Os folhelhos argilosos têm coloração cinza-escura e espessura milimétrica, enquanto as camadas claras são compostas de siltitos a arenitos muito finos, milimétricos a centimétricos (Figura $5 \mathrm{~A}, 5 \mathrm{~B}$, 5C). No topo das camadas escuras é comum a presença de icnofósseis (Figura 5D), classificados por TASSI (2010) como Cruziana, Rusophycus e Diplopodichnus, resultantes da bioturbação de sedimentos por, possivelmente, diplópodos.

A perfuração IT-IG 85 (Figura 1 - Ponto 6, Figura 6), realizada pelo Instituto Geológico do Estado de São Paulo (PETRI 1986), a cerca de 4 $\mathrm{km}$ a NNW do sítio urbano de Itu, seccionou $37 \mathrm{~m}$ de ritmito semelhante ao observado no parque. Em sua metade inferior, predominam, desde a base, diamictitos com matriz argilosa, com intercalações de ritmitos síltico-argilosos, assentando-se discordantemente sobre o embasamento pré-cambriano (a 261,5 m); a metade superior é composta por arenitos finos, sucedidos por ritmitos, semelhantes aos do Parque Geológico do Varvito de Itu (entre aproximadamente 51 a $13 \mathrm{~m}$ ), capeados por regolito argiloso, possivelmente alteração do ritmito.

Palinomorfos foram recuperados em dois testemunhos desta perfuração (a 171 e $228 \mathrm{~m}$ de profundidade), indicando posicionamento na Zona Crucisaccites monoletus, palinozona intermediária do Itararé (SOUZA et al. 2010). A presença, ainda que rara, de algas prasinofíceas (Deulisites tenuistriatus, Leiosphaeridia sp. e Tasmanites sp.) sugere influência marinha na sedimentação. Palinomorfos retrabalhados também foram constatados nestas duas amostras, típicos do Devoniano e Mississippiano, sugerindo reincorporação a partir de áreas fontes de tais idades.

Em termos de variação litológica, destaca-se o afloramento do entroncamento entre a SP-308 e
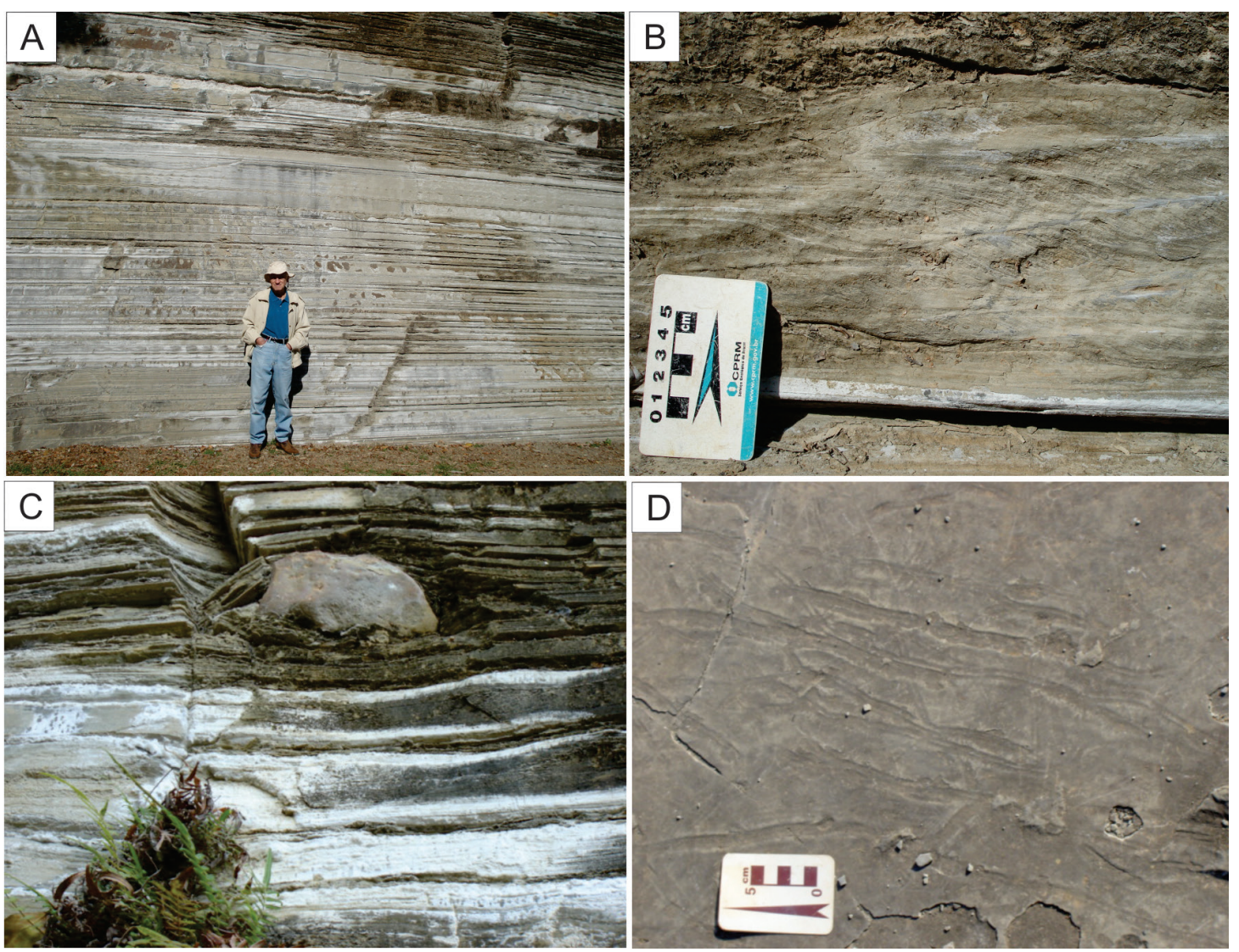

FIGURA 5 - (A) Ritmitos do Parque Geológico do Varvito em Itu. (B) Arenito muito fino com laminação cruzada cavalgante. (C) Clasto caído ( $10 \mathrm{~cm}$ ). D) Icnofósseis (Ano 2007). 


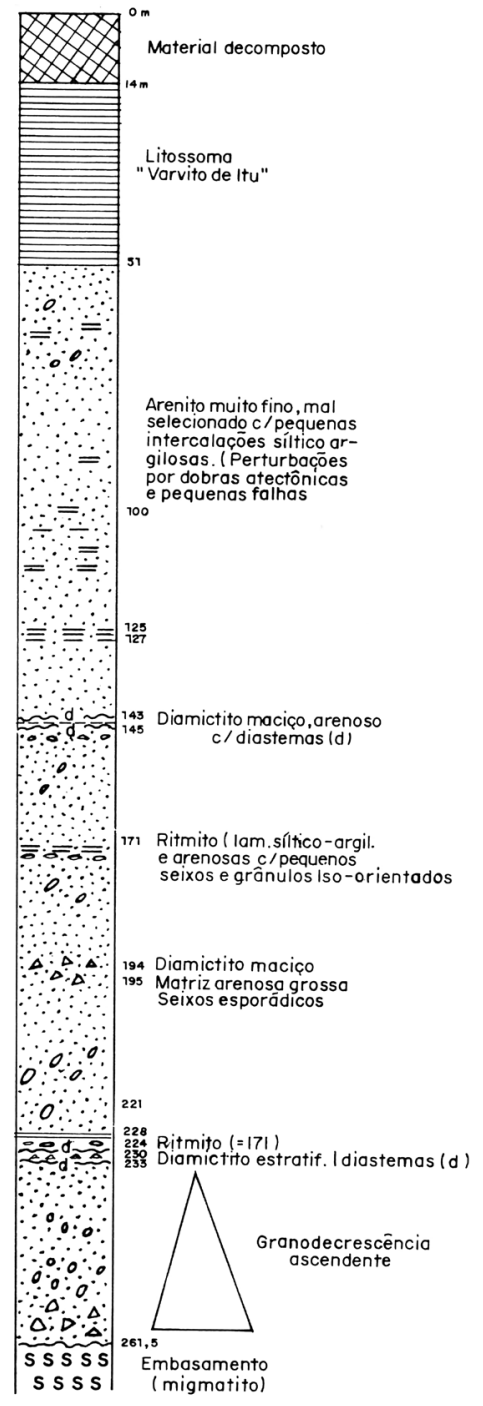

FIGURA 6 - Descrição do poço IT-IG 85 (Figura 1 - Ponto 6), realizada pelo Instituto Geológico do Estado de São Paulo (PETRI 1986).

a SP-75 (Figura 1 - Ponto 7, Figura 7A, B), alvo de estudos sedimentológicos de GAMA Jr. et al. (1992 a, b), SALVETTI (2005) e EZAKI (2011). Este afloramento apresenta as seguintes associações de litotipos, da base para o topo: (i) nível de conglomerado maciço, com cerca de 1-2 m de espessura, cimentado, em contato com arenitos médios a grossos na base e no topo (Figura 7C, $\mathrm{D}, \mathrm{E}$ ); (ii) ritmitos, arenitos e diamictitos suportados por matriz arenosa (Figura 7A); (iii) arenitos estratificados cortados por canais preenchidos por lamitos, folhelhos e diamictitos (Figura 7A); (iv) siltitos argilosos e maciços de aspecto tabular (Figura 7B). Estruturas de sobrecarga associadas à deformação glaciotectônica ocorrem no contato entre os diamictitos e folhelhos (Figura 7F).

LONGHIM et al. (2002) descreveram espécies de briófitas fósseis, esporos e grãos de pólen em ritmitos desse afloramento (Figura 7B), alguns característicos da Zona Crucisaccites monoletus, identificada por SOUZA et al. (2010) no poço IT-IG 85. Neste afloramento também foi reconhecida uma espécie de alga prasinofícea (Deusilites tenuistriatus), indicadora de salinidade no ambiente de sedimentação.

\section{Os registros da Pedreira Colonial}

A Pedreira Colonial (Figura 1 - Ponto 8 , Figura 8 ), a cerca de $2 \mathrm{~km}$ a leste do poço IT-IG 85 , tem sido estudada desde 1998 , com publicação do registro palinológico (SOUZA et al. 2010). Está atualmente abandonada e sua parte sudoeste (Figura 8 - pontos E e F) encontra-se recoberta por depósitos de rejeitos e aterros. Ainda assim, é notável a preservação da exposição na parte norte (Figura 8 - pontos B, C e D), onde estão registrados cerca de $20 \mathrm{~m}$ de ritmitos e diamictitos do Grupo Itararé da área-Itu (Figuras 9 e 10).

Esta sucessão pode ser dividida em duas partes (Figuras 9 e 10). A basal apresenta domínio de ritmitos heterolíticos pelíticos (Figura 11 A, B, C), geralmente, compostas de folhelhos pretos laminados intercalados com lâminas de siltitos cinzas claros (Figura 11D) que, eventualmente, alcançam $1 \mathrm{~cm}$ de espessura. Localmente, podem ocorrer camadas de até $5 \mathrm{~cm}$ de arenitos muito finos com marcas onduladas (Figura 11E), bem como clastos caídos centimétricos (Figura 11F). De modo geral, esta sucessão é homogênea ao longo dos $15 \mathrm{~m}$ de exposição. $\mathrm{O}$ que varia bastante são as atitudes do acamamento dos depósitos geralmente sub-horizontais $(242 / 07,230 / 08)$, mas que podem passar, lateral ou verticalmente, a subvertical. Nesses folhelhos foram feitas coletas (Figuras 8E, 11G) para estudos palinológicos, publicados em SOUZA et al. (2010).

$\mathrm{O}$ contato com as fácies superiores encontra-se encoberto por colúvios atuais (Figura 12A). O pacote superior é constituído de diamictitos maciços a fracamente estratificados, sustentados por matriz areno-argilosa com seixos e blocos esparsos (Figura 12B, C). Os clastos maiores são constituídos de quartzo e, subordinadamente, fragmentos de rochas, principalmente graníticas, que podem atingir até $10 \mathrm{~cm}$ de diâmetro. A maioria deles é facetada e alguns estriados (Figura 12D, E). A espessura dos diamictitos alcança $4 \mathrm{~m}$ 

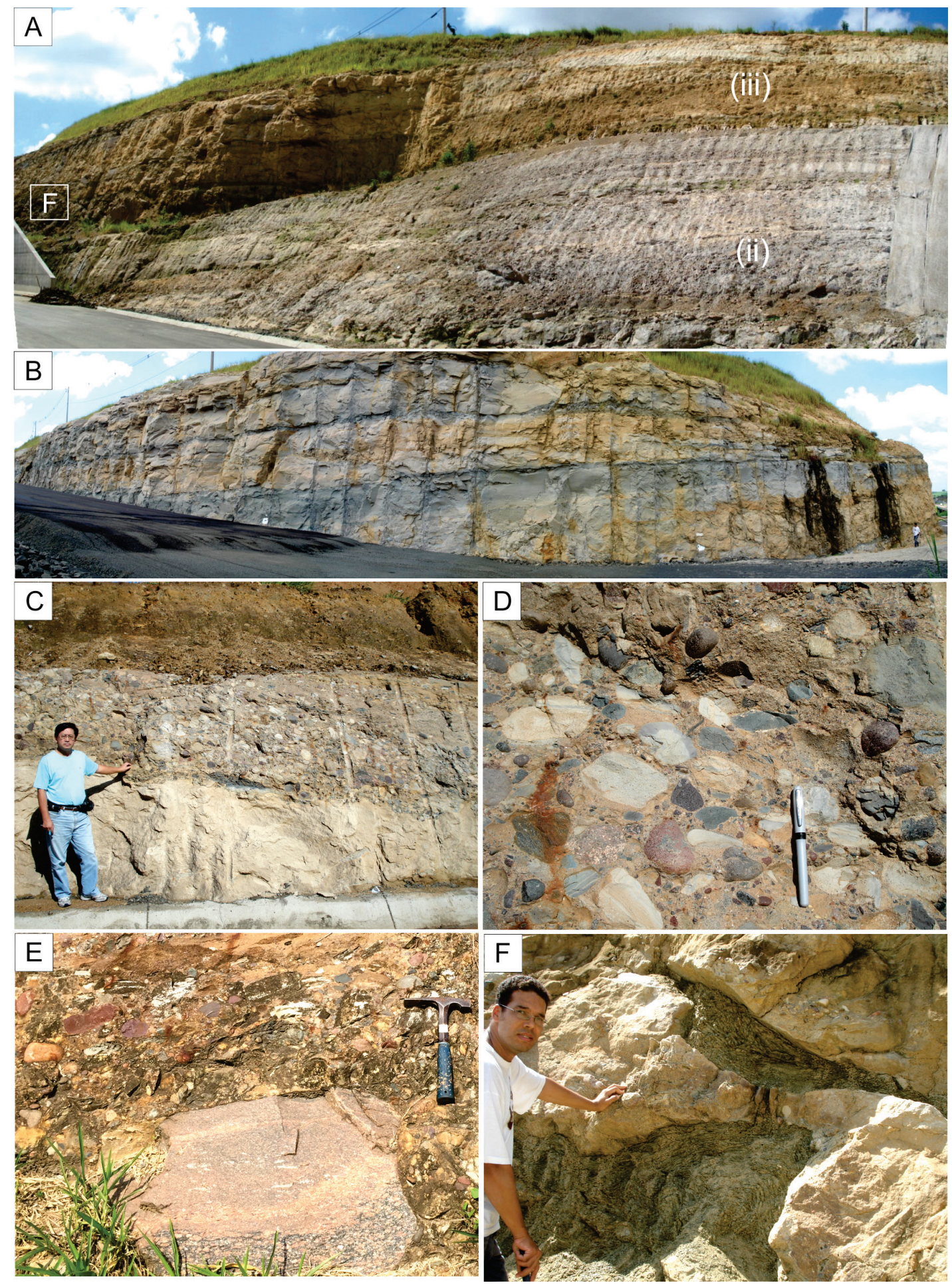

FIGURA 7 - Corte de estrada no entroncamento entre a SP-308 e a SP-75. (A) Pacote inferior do afloramento, constituído por arenitos e diamictitos (ii), recobertos por associação de arenitos, ritmitos, diamictitos e folhelhos (iii) (Ano 2009). (B) Pacote superior do afloramento, constituído por siltitos maciços; na base desse corte ocorrem ritmitos, onde foram amostrados palinomorfos por LONGHIM et al. (2002) (Ano 2009) (C) e (D) Nível de conglomerado na base do afloramento (Ano 2009). (E) Detalhe do conglomerado, composto por clastos de quartzito, granito, gnaisse, siltito, arenito, entre outras litologias (Ano 2015). (F) Deformação glaciotectônica causada pela deposição do diamictito sobre folhelhos ainda no estado plástico (vide localização da feição em A) (Ano 2007). 


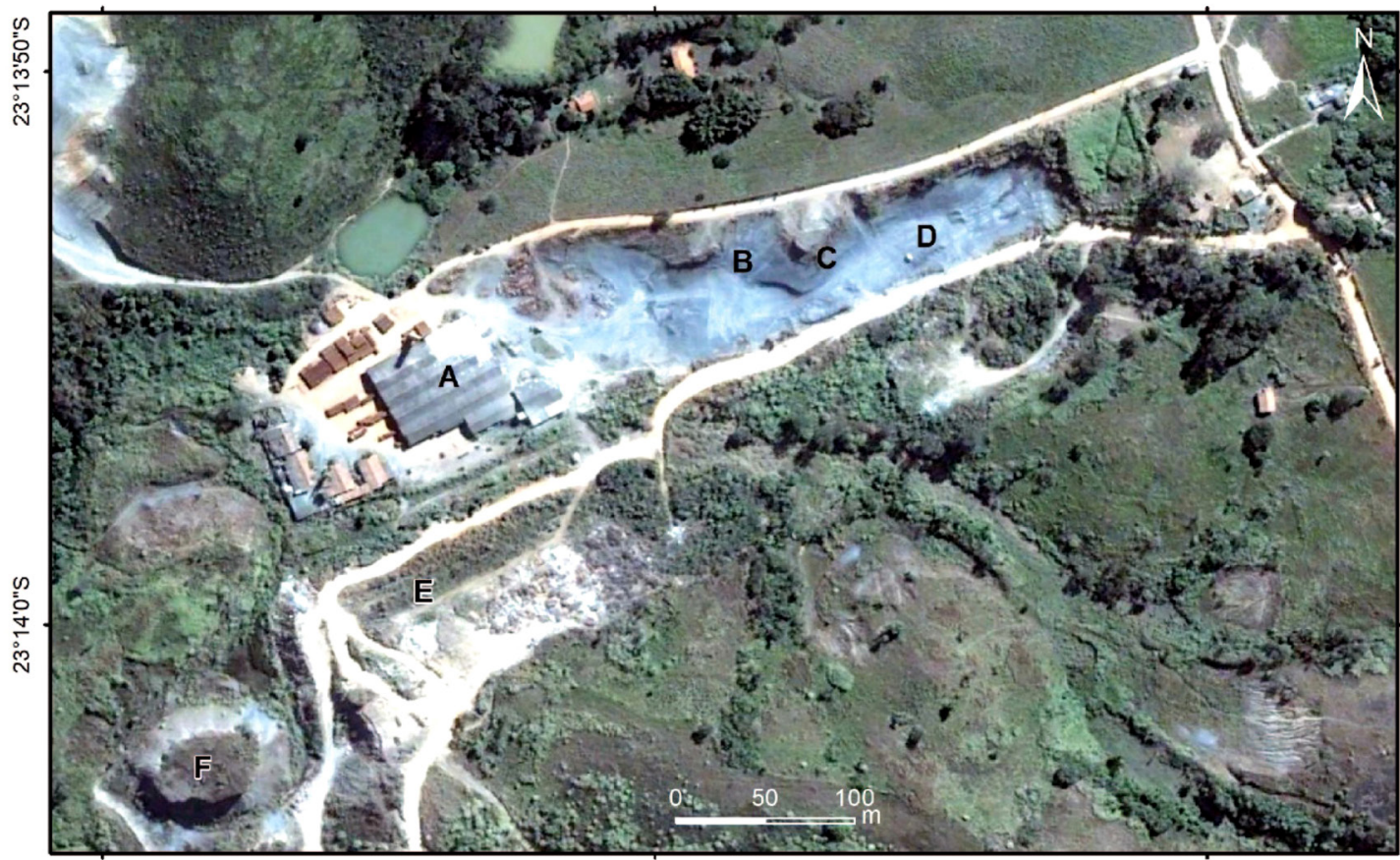

$47^{\circ} 20^{\prime} 0^{\prime \prime O}$

$47^{\circ} 19^{\prime} 50 " \mathrm{O}$

$47^{\circ} 19^{\prime} 40 " \mathrm{O}$

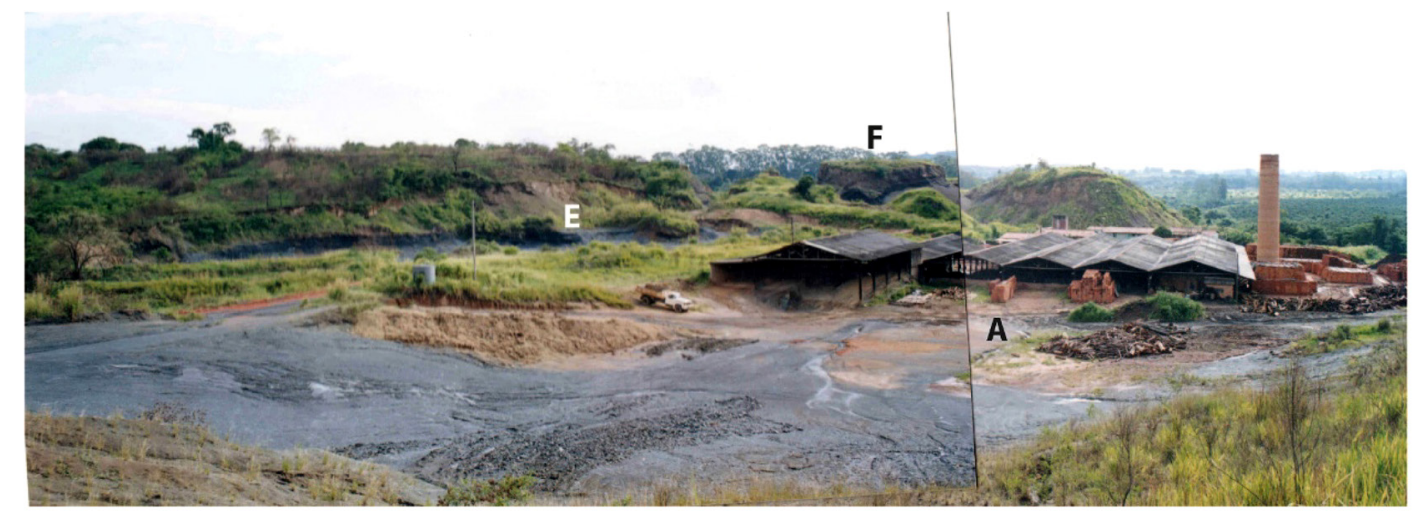

FIGURA 8 - Imagem Google Earth de 2005 ilustrando a área da Pedreira Colonial em atividade. Abaixo, vista geral da pedreira no ano de 1999. O ponto A corresponde às instalações industriais. Os pontos B e C correspondem ao local da seção esquemática da figura 9. O ponto D corresponde a um matacão de granito ilustrado na figura 13 . O ponto E (Figura $11 \mathrm{G}$ ) é o local de coleta para análise de palinomorfos realizado por SOUZA et al. (2010).

e na base, em contato irregular, passam para argilitos laminados, pobremente exposto $(\sim 0,5 \mathrm{~m}$ de espessura) devido ao recobrimento por colúvios atuais. Nesse contato é possível observar estruturas deformacionais causadas pela sobrecarga e arrasto do diamictito sobre o argilito quando os sedimentos ainda se encontravam inconsolidados, em estado plástico, associadas ao avanço da geleira (Figura 12F).

A presença no centro da pedreira de um matacão de rocha granítica com diâmetro maior que $2 \mathrm{~m}$, é sugestiva que o mesmo, possivelmen- te, fazia parte do nível dos diamictitos, ou, ainda, corresponderia a um megaclasto caído, que ali fora disposto pela erosão superficial durante o processo de lavra (Figura 13A, B). Quanto à sua composição, trata-se de um granito porfirítico de cor avermelhada (Figura 13C), com fenocristais de feldspato potássico, com matriz inequigranular, constituída basicamente de quartzo, feldspato potássico, plagioclásio e biotita.

$\mathrm{Na}$ pedreira podem ser identificadas feições de deformação do acamamento possivelmente associadas a processos de tensões glacio- 


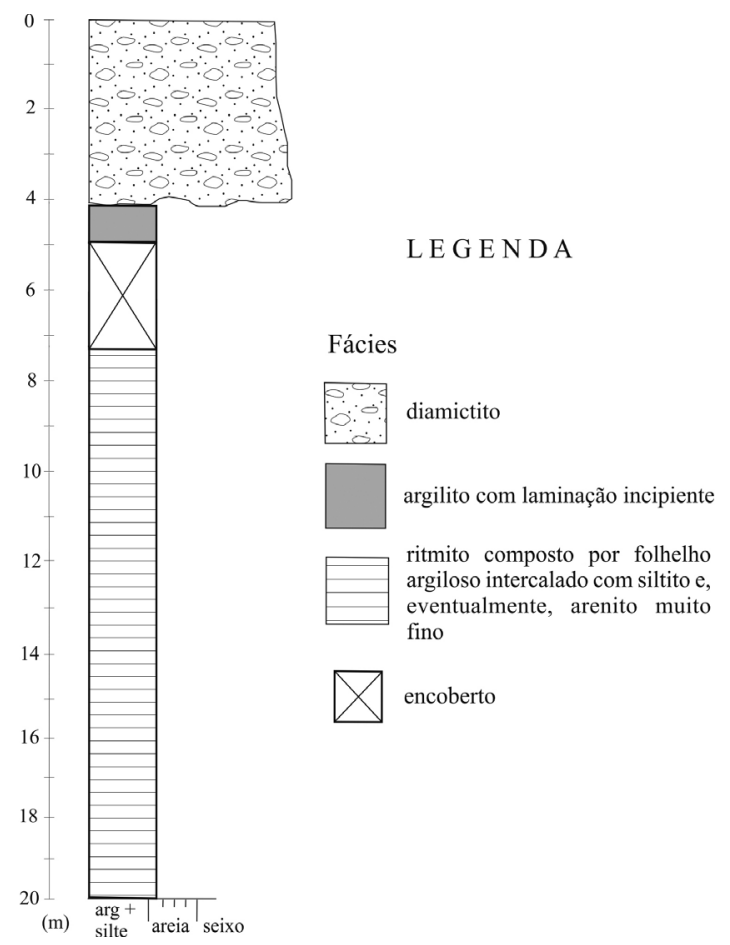

FIGURA 9 - Seção colunar esquemática dos depósitos do Grupo Itararé na área-Itu com domínio de ritmitos compostos de depósitos heterolíticos de folhelhos argilosos pretos intercalados com laminas de siltito cinza claro (Figura 11A-C). Localmente podem ocorrer intercalações de arenitos muito finos (Figura 11E). A parte superior é constituída de argilito fracamente laminado sotoposto a $4 \mathrm{~m}$ de diamictito maciço. Seção levantada nos pontos $\mathrm{B}$ e $\mathrm{C}$ da figura 8).

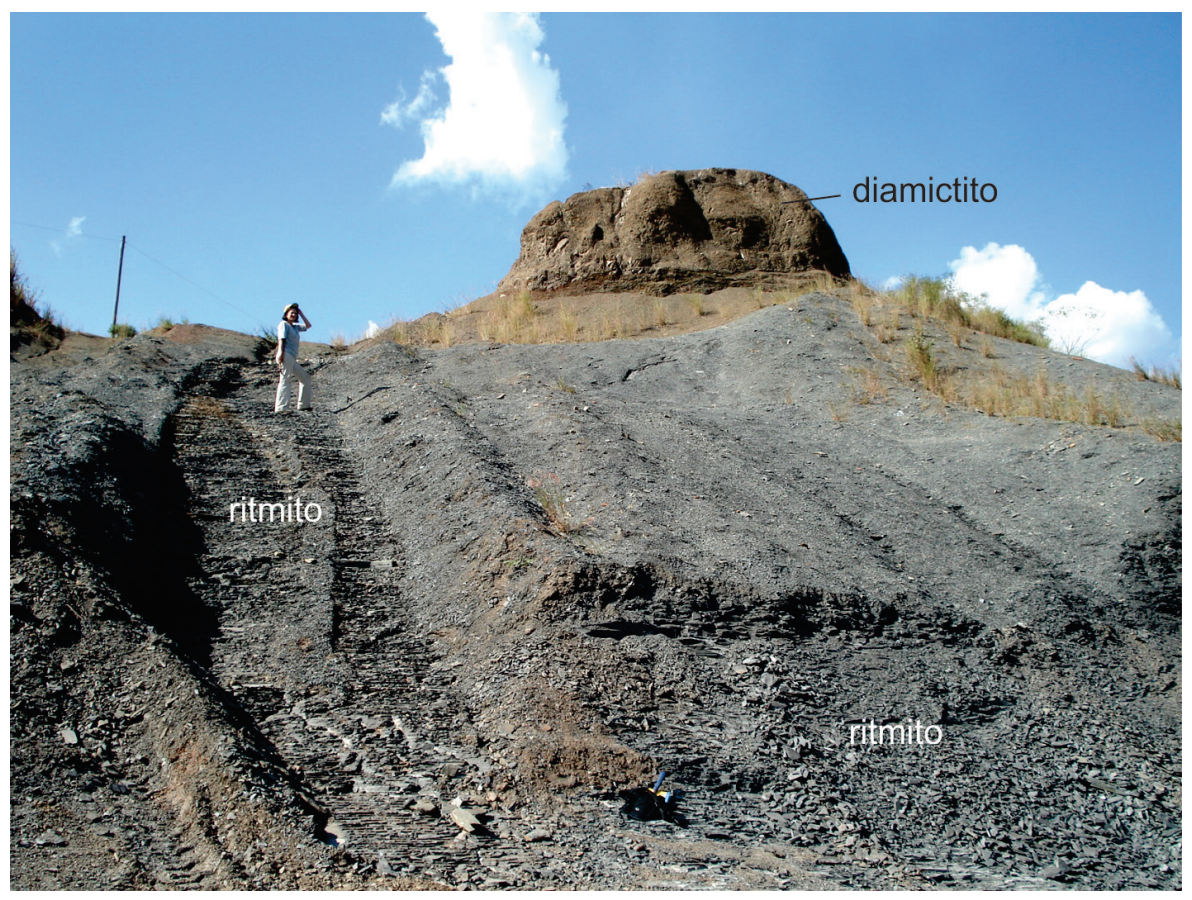

FIGURA 10 - Vista geral da sucessão sedimentar da Pedreira Colonial (Figura 8, ponto C). Notar que o domínio é dos depósitos aquoso-glaciais, representados pelos ritmitos, que estão recobertos por cerca de $4 \mathrm{~m}$ de diamictitos (Ano 2007). 

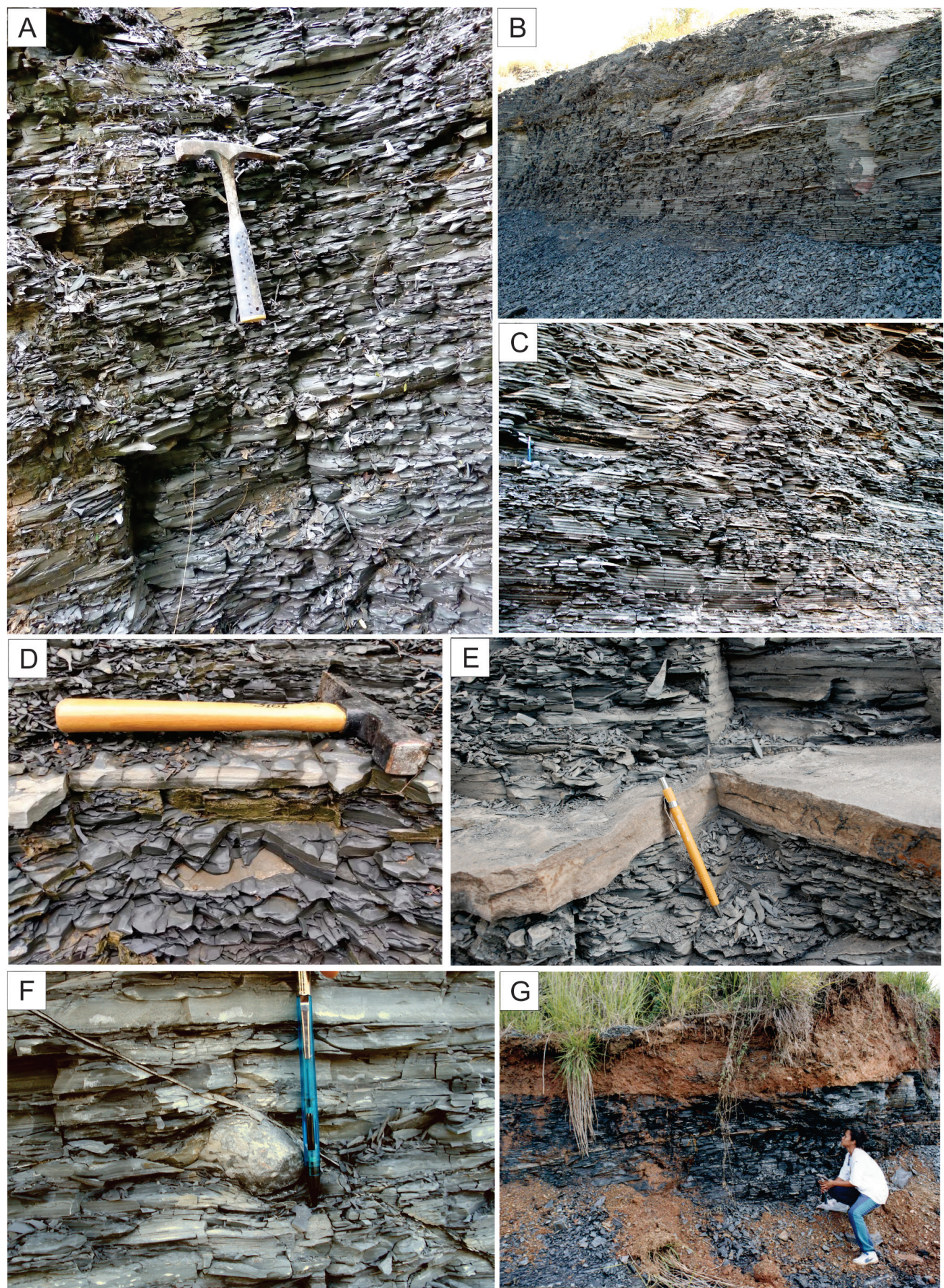

FIGURA 11 - Parte inferior da seção colunar - ritmitos (Figura 9). (A) (Ano 2019), (B) (Ano 2007) e (C) (Ano 2007): Ritmito composto de folhelho argiloso com alternância de lâminas de siltito branco (D) (Ano 2019). (E) Localmente, ocorrem intercalações centimétricas de arenitos muito finos com marcas onduladas (Ano 2007). (F) Clasto caído centimétrico no ritmito. Notar plano de falha rúptil, pós-deposicional, oblíquo ao acamamento conjugado a outro com atitude subparalelizada à estratificação (Ano 2007). (G) Ritmitos compostos de folhelhos negros, alternados com finas camadas de argilitos mais claros, com estratificação plano-paralela, com alguns níveis carbonáticos (claros) (Ano 1999). Seção (Figura 8, ponto E) onde foi feita coleta para estudos palinológicos publicados em SOUZA et al. (2010). 

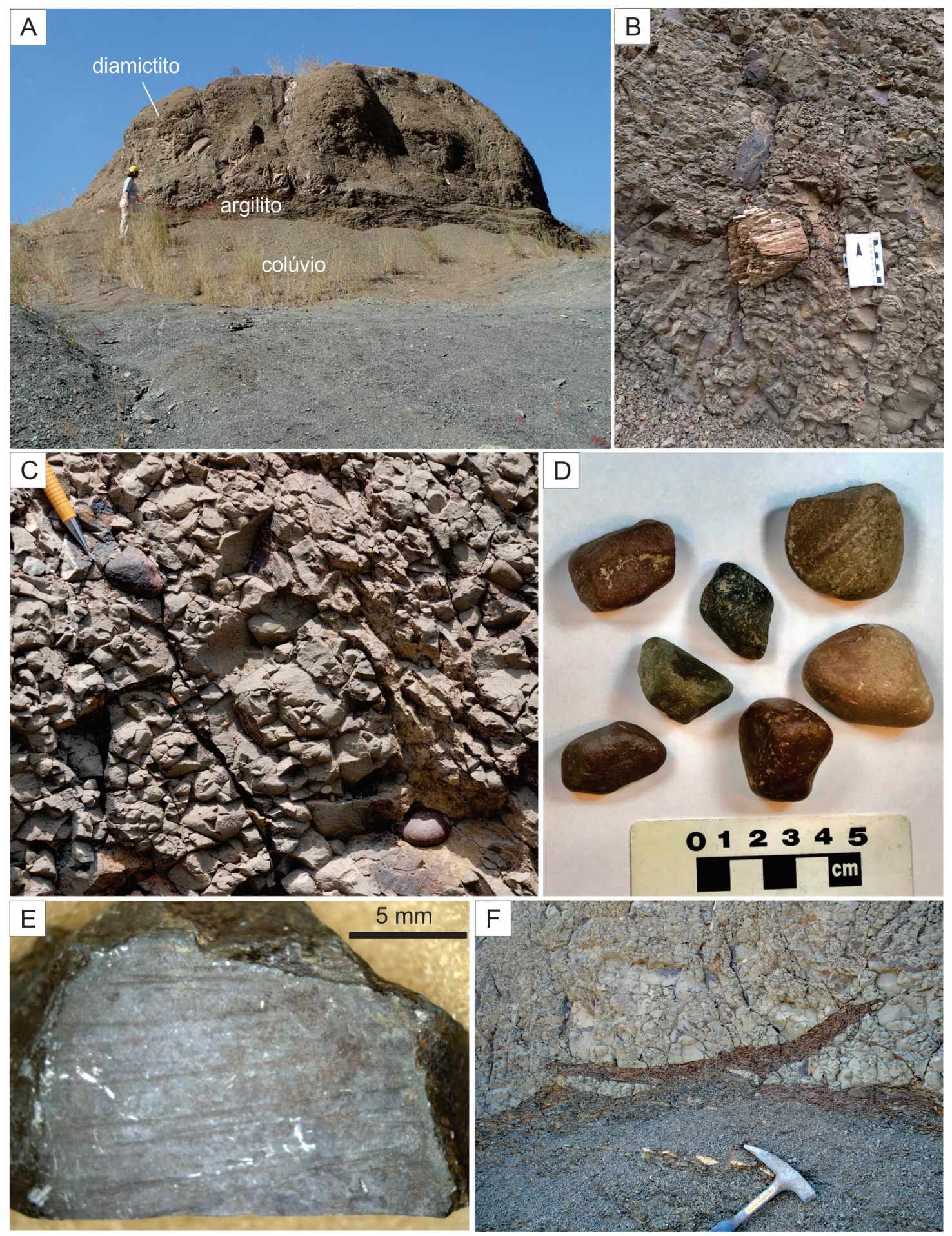

FIGURA 12 - Parte superior da seção colunar (Figura 8, ponto C; Figura 9). (A) Argilito laminado (base) em contato com diamictito (topo) (Ano 2007). Diamictito com clastos dispersos de granito (B) (Ano 2019) e de quartzo (C) (Ano 2007) em matriz areno-argilosa maciça. Clastos facetados (D) e com estrias (E) (Ano 2019) associados com o processo glacial. (F) Estrutura deformacional causada pela sobrecarga e arrasto do diamictito sobre o argilito quando ainda estava no estado plástico (Ano 2007). 

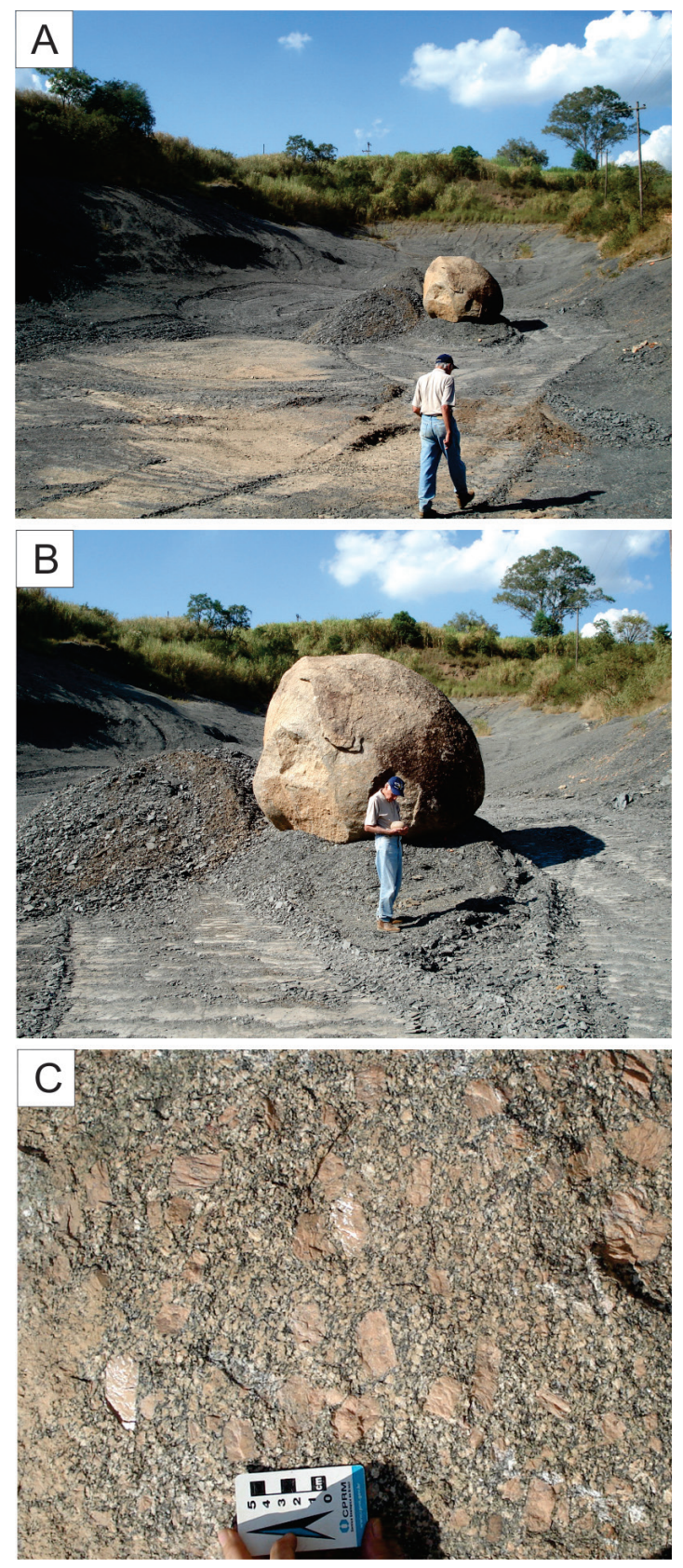

FIGURA 13 - (A) Matacão de granito situado no centro da pedreira (Figura 8, ponto D), que possivelmente fazia parte do diamictito, ou corresponderia a um megaclasto caído. (B) Detalhe da foto anterior. (C) Detalhe do granito porfirítico do matacão (Ano 2007).

tectônicas, aqui interpretadas como relacionadas à deformação dos pacotes sedimentares, pré-litificação (Figura 14). As fotos ilustram níveis de ritmitos com dobras suaves e irregulares intercaladas com níveis sem deformação do acamamento. Diversos planos de falhas rúpteis preenchidos
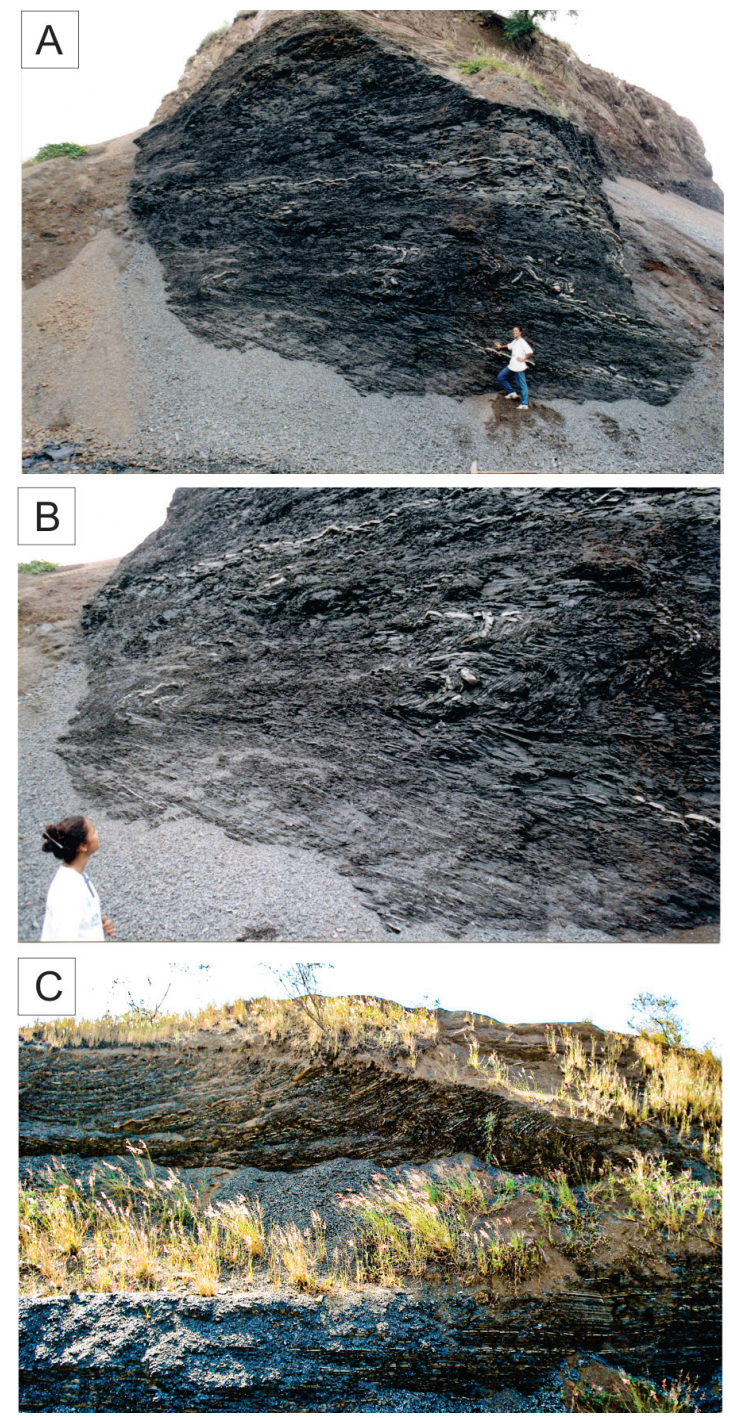

FIGURA 14 - Ritmitos com dobras associadas à tectônica gravitacional sinsedimentar (soft-sediment deformation). (A) (Ano 1999) e (B) (Ano 1999) Detalhe dos ritmitos compostos de folhelhos negros, alternados com finas camadas de siltitos mais claros, apresentando conjunto de dobras suaves e irregulares associado aos processos glaciais (Figura 8, ponto F). (C) Seção dos ritmitos com níveis indeformados (na base) e deformados (no topo). Notar que a parte deformada e confinada no pacote sedimentar, apresenta um padrão de dobramentos relativamente irregular (Ano 2007).

por calcita, de espessura milimétrica, subparalelos e oblíquos ao acamamento, representam fenômenos tectônicos pós-deposicionais (Figura 15). Observou-se ainda que os ritmitos encontram-se fraturados, com veios de quartzo e pirita nele disseminados. 


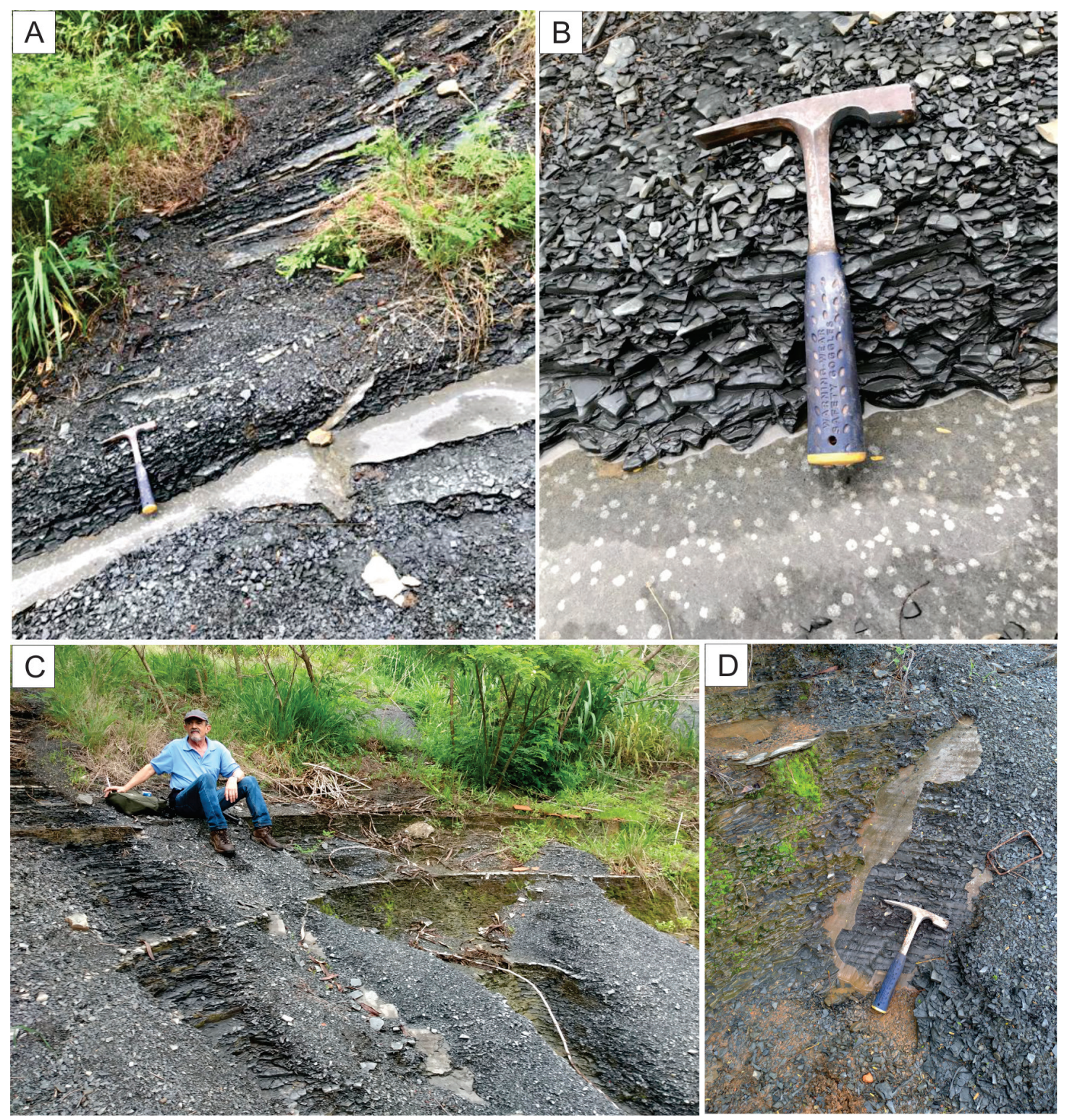

FIGURA 15 - Ritmitos afetados por falhas pós-deposicionais preenchidas por calcita (espessura milimétrica) (Figura 8, ponto B). Planos de falha paralelos ao acamamento (A, B, C) e oblíquos (D - plano de falha 268/35 estriado com caráter normal). Notar que os planos de falhas rúpteis preenchidos por calcita destacam-se pela coloração branca a rósea, o que as distingue das lâminas siltosas (cinza claro) e argilosas (preto). A calcita, mineral secundário nos depósitos Itararé, substituiu o material da "zona” cominuída pelo cisalhamento (Ano 2019).

\section{DISCUSSÃO}

$\mathrm{Na}$ área-Itu estão presentes espessos depósitos aquoso-glaciais, que atingem $300 \mathrm{~m}$ (ODA 1998). Os ritmitos do Parque Geológico do Varvito e da Pedreira Colonial correspondem provavelmente ao nível superior da sondagem IG-IT-85, sendo correlatos do ponto de vista palinológico (SOUZA et al. 2010).
Os ritmitos do Parque Geológico do Varvito caracterizam-se pela predominância de camadas claras de siltito e arenito fino, atribuídas a fluxos densos trazidos por sistemas fluviais de água de degelo (CAETANO-CHANG \& FERREIRA 2006). A presença de Rusophycus, identificada por TASSI (2010) e observada também por BALISTIERI (2003) e LERMEN (2006) em ritmitos do Grupo Itararé nos estados de Santa Catarina e Rio Grande 
do Sul, é sugestiva de ambiente marinho. Além disso, algas prasinofíceas identificadas nos ritmitos do "varvito de Itu", bem como nas duas amostras do poço IT-IG 85 por SOUZA et al. (2010), reforçam a influência marinha na sedimentação. Contudo, a baixa quantidade de espécimes deste tipo algálico pode ser resultado do predomínio de água de degelo, em ambiente transicional. Os estudos icnológicos de TASSI (2010), assim como os de BALISTIERI (2003), LERMEN (2006) e GANDINI et al. (2007) apontam águas rasas para os ritmitos Itararé.

Nos ritmitos da Pedreira Colonial, siltitos e folhelhos são predominantes, indicando processos de suspensão e decantação em ambiente aquoso de baixa energia e redutor. Sobreposto aos ritmitos, ocorrem diamictitos com clastos facetados e estriados - tilitos, associado a ambientes subglaciais. Estes depósitos avançaram enquanto os sedimentos pelíticos ainda estavam pouco consolidados, gerando dobras irregulares (Figura 14), tal como observado em outro afloramento a norte (Figura 1 - Ponto 7), no entroncamento da SP-308 e a SP-75, onde folhelhos sotopostos a diamictitos também apresentam laminação deformada (Figura 7F). A sucessão sedimentar (Figura 7) do afloramento do entroncamento entre a SP-308 e a SP-75 é sugestiva de dominância de depósitos aquoso-glaciais.

O zoneamento palinoestratigráfico integrado em SOUZA \& MARQUES-TOIGO (2005) e SOUZA (2006) tornou-se ferramenta indispensável para os estudos do Neopaleozoico da Bacia do Paraná. SOUZA et al. (2010) verificaram a presença da Zona Crusaccites monoletus, reconhecida originalmente por SOUZA (2006) na porção média do Grupo Itararé. Os sedimentos do poço IT-IG 85, das pedreiras Colonial e Ituana, do entroncamento da SP-308 com a SP-75, bem como do Parque Geológico do Varvito, estão dentro da Zona Crucisaccites monoletus (SOUZA et al. 2010). Estas informações, aliadas às datações radiométricas (CAGLIARI et al. 2016; GRIFFIS et al. 2018, 2019; ROCHA-CAMPOS et al. 2019), atestam o posicionamento geocronológico da área-Itu no Pennsylvaniano (Kasimoviano-Gzheliano).

Até o momento, não são conhecidos estudos bioestratigráficos e geocronológicos na aqui denominada área-Salto. É possível que os estratos de Salto sobre os granitos sejam os registros mais basais e antigos do Grupo Itararé na área, colocados adjacentes aos estratos mais recentes da área-Itu em função da reativação tectônica pós-deposicional da Falha de Itu. Mudanças nas espessuras dos estra- tos na Bacia do Paraná devem ter sido influenciadas por eventos tectônicos sin-deposicionais, pelo menos durante as fases iniciais do Grupo Itararé (EYLES \& EYLES 1993, EYLES et al. 1993) e pós-deposicionais (NEVES 2005, EZAKI 2011). ODA et al. (2012, figura 5, perfil 10) sugere a existência de uma falha normal a oeste de Salto, onde as espessuras dos estratos crescem significativamente; o posicionamento dessa falha é coincidente com o prolongamento da Falha de Itu a noroeste. As falhas observadas na Pedreira Colonial registram também a tectônica pós-deposicional, associada a eventos pós-ruptura do Gondwana Ocidental.

A faixa oriental da Bacia do Paraná no sudeste do Brasil, em especial no Estado de São Paulo, no contexto da LPIA, destaca-se pelo fato dos depósitos do Grupo Itararé estarem diretamente conectados com feições glaciais da região da Namíbia (VESELY et al. 2015). Conforme LIMARINO et al. (2014), o primeiro estágio glacial (Viseano a Bashkiriano inicial) caracteriza-se pelas mais intensas manifestações glaciais da história da LPIA do Gondwana. Depósitos glaciais relacionados ao primeiro estágio estariam representados na base do Grupo Itararé, com representação sedimentar significativa no Estado de São Paulo. Estruturas erosivas indicativas de fluxo glacial, como as rochas moutonnées, só foram identificadas no Estado de São Paulo, na área-Salto. As moutonnées são indicativas das mais fortes ações erosivas glaciais; fora do Brasil ocorre na Namíbia, local considerado como polo da glaciação permo-carbonífera. Outras feições glaciais não mostram sinais de partes do embasamento rochoso ou resistente, arrancadas a jusante pelo gelo. A tabela publicada por ROSA et al. (2016, p. 33), baseada em BENNET \& GLASSER (2009) e BENN \& EVANS (2010), separa as diferentes formas de terreno geradas pela ação erosiva do gelo. As de Salto são de meso a macroescala e só ocorrem nas camadas mais basais de uma sucessão de depósitos glaciais e as únicas que são classificadas como moutonnées. Os avanços das geleiras foram decisivos na esculturação do substrato pré-Itararé. Além da rocha moutonnée, diversas outras feições erosivas foram descritas na Bacia do Paraná, tais como paleovales glaciais em Santa Catarina (FALLGATTER \& PAIM 2019) e whalebacks no Uruguai (ASSINE et al. 2018), entre outras.

O centro-oriental da faixa que limita a Bacia do Paraná tem sulcos glaciais com sentido do movimento do gelo para NW ou NNW, registrado desde a primeira medida da rocha moutonnée (ALMEIDA 1948). As superfícies estriadas identi- 
ficadas no pavimento Guaraú, na área-Salto, resultaram em medidas com direção média de N48W, com mergulho variando entre 12 e $42^{\circ}$ para SE (PÉREZ-AGUILAR et al. 2009). Essas medidas estão em plena conformidade com os dados obtidos e sintetizados para o Itararé e Aquidauana no âmbito de toda a Bacia do Paraná por GESICKI et al. (2002) e constituem importante ferramenta para o entendimento da dinâmica glacial. Tais medidas podem variar de sentido e, ao longo do tempo, os centros glaciais se modificaram no tempo e no espaço (MOTTIN et al. 2018). Admitindo-se a hipótese do Itararé estar restrito ao Carbonífero, as áreas Salto e Itu estariam mais próximas ao centro glacial inferido na Namíbia.

\section{CONSIDERAÇÕES FINAIS}

No âmbito do Grupo Itararé, as áreas aqui designadas de Salto e Itu exibem feições glaciais ímpares em uma área de cerca de $100 \mathrm{~km}^{2}$, de caráter, respectivamente, erosivo (pavimentos estriados, clastos estriados e rochas moutonnées) e deposicional (depósitos espessos de ritmitos, folhelhos e diamictitos).

Mesmo em uma pequena extensão, é notável a diversidade faciológica do Grupo Itararé na área-Itu, evidente ao se confrontar as diferenças litológicas entre as exposições da Pedreira Colonial e do Parque Geológico do Varvito: ambas as exposições representam corpos aquosos de baixa energia, de águas rasas, porém com variações nas contribuições de fácies arenosas durante a fase de degelo. Outra diferenciação entre os dois registros é a de que na Pedreira Colonial, a última deposição (diamictitos) correspondeu à retomada de depósitos subglaciais sobre sedimentos aquoso-glaciais (ritmitos) ainda no estado plástico, o que gerou deformação na laminação dos ritmitos. Por isso, é comum nesta pedreira a presença de feições glaciotectônicas, ausentes no Parque Geológico do Varvito.

As rochas moutonnées de Salto, únicas ocorrências no Brasil, possuem similares apenas na Namíbia, considerado o centro glacial no Carbonífero. Além dessas estruturas, as demais feições da área-Salto atestam a alta energia do processo erosivo glacial.

A palinozona Crucisaccites monoletus foi detectada em materiais da área-Itu (Parque Geológico do Varvito, Pedreira Colonial, poço IT-IG 85 e entroncamento da SP-308 com a SP-75). Desta forma, a área-Itu tem posicionamento geocronológico no Pennsylvaniano. Evidentemente, a idade relativa entre cada uma dessas ocorrências, tanto em superfície quanto em subsuperfície, é variada neste intervalo de tempo. Considerando a heterogeneidade dos corpos sedimentares a curtas e longas distâncias, bem como ausência ou escassez de camadas guias, há necessidade de um trabalho minucioso de levantamento e empilhamento estratigráfico em escala de maior detalhe para elucidar a sucessão dos eventos glaciais, além de novos estudos palinológicos, principalmente na área-Salto, onde os depósitos são menos expressivos.

O Grupo Itararé tem sido alvo de importantes contribuições científicas de diferentes autores ao longo das últimas décadas com avanços expressivos no entendimento global da $L P I A$, no que se refere aos seus paleoambientes e à sua cronologia relativa e absoluta. Dada a magnitude do registro geológico das áreas Itu-Salto, onde o evento LPIA deixou as marcas mais vigorosas de sua presença (moutonées) e os registros possivelmente mais antigos do Grupo Itararé, urge que novas pesquisas com levantamentos estratigráfico, estrutural, palinológico, paleoambiental, geocronológico sejam empreendidas nessa região, assim como no restante do Estado de São Paulo.

\section{AGRADECIMENTOS}

Ao Prof. Dr. Mario Luis Assine pela revisão do artigo e sugestões que enriqueceram o artigo. Ao Pesquisador Científico Dr. Antonio Luiz Teixeira pela colaboração nos trabalhos de campo e revisão do artigo. Paulo Alves de Souza agradece ao CNPq pela concessão de bolsa de produtividade em pesquisa (Processo 313340/2018-8).

\section{REFERÊNCIAS BIBLIOGRÁFICAS}

AB'SÁBER, A.N. 1948. A transição entre o Carbonifero e o Criptozoico na região de Itu. Mineração e Metalurgia, 12(71): 221-223.

ALMEIDA, F.F.M. 1948. A "roche moutonnée" de Salto, Estado de São Paulo. Geologia e Metalurgia, 5:112- 118.

ALMEIDA, F.F.M. 1959. Guia de Excursão: São Paulo a Araraquara. In: SBG, CONGRESSO BRASISLEIRO DE GEOLOGIA, 13, São Paulo, Guia de Excursão, 12 p.

ALMEIDA, F.F.M. 2018. Fundamentos geológicos do relevo paulista. Revista do Instituto Geológico, 39(3): 9-75. Republicado de 
ALMEIDA, F.F.M. 1964. Fundamentos geológicos do relevo paulista. Boletim do Instituto Geográfico e Geológico, 41: 169-262. https:// doi.org/10.33958/revig.v39i3.600

AMARAL, S.E. 1965. Nova ocorrência de rocha moutonné em Salto, SP. Boletim da Sociedade Brasileira de Geologia, 14(1/2):71-82.

ASSINE,M.L.;SANTA ANA,H.;VEROSLAVSKY, G.; VESELY, F. 2018. Exhumed subglacial landscape in Uruguay: Erosional landforms, depositional environments, and paleo-ice flow in the context of the late Paleozoic Gondwanan glaciation. Sedimentary Geology, 369: 1-12. https://doi.org/10.1016/j.sedgeo.2018.03.011.

BALISTIERI, P.R.M.N. 2003. Paleoicnologia da porção superior do Grupo Itararé na região de Mafra (SC): limitações paleoecológicas, paleoambientais e estratigráficas. UNISINOS, São Leopoldo, Tese de Doutorado, 247 p.

BENN, D.I.; EVANS, D.J.A. (eds.). 2010. Glaciers and Glaciation. Hodder Education, London, $817 \mathrm{p}$.

BENETT, M.R.; GLESSER, N.F. 2009. Glacial Geology - Ice Sheets and Landforms. WileyBlackwell, Chichester, 385 p.

CAETANO-CHANG, M.R.; FERREIRA, S.M. 2006. Ritmitos de Itu: petrografia e considerações paleodeposicionais. Geociências, 25 (3): 345-358.

CAGLIARI, J.; PHILIPP, R.P.; VALDEZ BUSO, V.; GUIMARÃES NETTO, R.; HILLEBRAND, P.K.; LOPES, R.C.; BASEI, M.A.S.; FACCINI, U.F. 2016. Age constraints of the glaciation in the Paraná Basin: evidence from new U-Pb dates. Journal of the Geological Society, 173: 871-874. https://doi.org/10.1144/ jgs2015-161

CASTRO, J.C.; WEINSCHÜTZ, L.C.; CASTRO, M.R. 2005. Estratigrafia de sequências das formações Taciba e Rio Bonito (Membro Triunfo) na região de Mafra/SC, leste da Bacia do Paraná. Boletim de Geociências da Petrobrás, 13 (1): 27-42.

DE MARTONNE, E. 1940. Problèmes morphologiques du Brésil tropical atlantique. Annales de Géographie, 49 (277): 1-27 e (278-279): 106-129.
EYLES, N.; EYLES, C.H. 1993. Glacial geologic confirmation of an intraplate boundary in the Paraná basin of Brazil. Geology, 21(5): 459-462. https://doi.org/10.1130/00917613(1993)021\%3C0459:GGCOAI\%3E2.3. $\mathrm{CO} ; 2$

EYLES, C.H.; EYLES, N.; FRANÇA, A.B. 1993. Glaciation and tectonics in an active intracratonic basin: the Late Palaeozoic Itararé Group, Paraná Basin, Brazil. Sedimentology, 40(1): 1-25. https://doi. org/10.1111/j.1365-3091.1993.tb01087.x

EZAKI, S. 2011. Hidrogeoquímica dos aquíferos Tubarão e Cristalino na região de Salto (SP). Instituto de Geociências, Universidade de São Paulo, Tese de Doutorado, São Paulo, 180 p. https://doi.org/10.11606/T.44.2011. tde-17082011-092345

FALlGATTER, C.; PAIM, P.S.G. 2019. On the origin of the Itarare Group basal nonconformity and its implications for the Late Paleozoic glaciation in the Paraná Basin, Brazil. Palaeogeography, Palaeoclimatology, Palaeocology, 531, Part B, 108225. https:// doi.org/10.1016/j.palaeo.2017.02.039

FIELDING, C.R.; FRANK, R.D.; ISBELL, J.L. 2008. The late Paleozoic ice age - a review of current undestanding and synthesis of global climate patterns. The Geological Society of America, Special Paper, 441: 343-354. https:// doi.org/10.1130/2008.2441(24)

FRANÇA, A.B.; POTTER, P.E. 1988. Estratigrafia, ambiente deposicional e análise de reservatório do Grupo Itararé (Permo-Carbonífero), Bacia do Paraná (parte 1). Boletim de Geociências da Petrobrás, 2(4): 147-191.

FRANÇA, A.B.; POTTER, P.E. 1991. Stratigraphy and Reservoir Potential of Glacial Deposits of the Itarare Group (Carboniferous-Permian), Parana Basin, Brazil (1). AAPG Bulletin, 75(1): 62-85.

GAMA Jr., E.; PERINOTTO, J.A.J.; RIBEIRO, H.J.P.S.; PADULA, E.K. 1992a. Contribuição ao estudo da ressedimentação no Subgrupo Itararé: um guia temático de campo. Revista Brasileira de Geociências, 22(2): 237-247. http://dx.doi.org/10.25249/03757536.1992237247 
GAMA Jr., E.; PERINOTTO, J.A.J.; RIBEIRO, H. J. P.; PADULA, E.H. 1992b. Contribuição ao estudo da ressedimentação no Grupo Itararé: tratos de fácies e hidrodinâmica deposicional. Revista Brasileira de Geociências, 22(2): 228-236. http://dx.doi.org/10.25249/03757536.1992228236

GANDINI, R.; GUIMARÃES NETTO, R.; SOUZA, P.A. 2007. Paleoicnologia e a palinologia dos ritmitos do Grupo Itararé na pedreira de Águas Claras (Santa Catarina, Brasil). GAEA - Journal of Geoscience, 3(2): 47-59.

GESICKI, A.L.D.; RICCOMINI, C.; BOGGIANI, P.C. 2002. Ice flow direction during late Paleozoic glaciation in western Paraná Basin, Brazil. Journal of South American Earth Sciences, 14:933-939. https://doi.org/10.1016/ S0895-9811(01)00076-1

GRIFFIS, N.P.; MUNDIL, R.; MONTAÑEZ, I.P.; ISBELL, J.L.; FEDORCHUK, N. D.; VESELY, F.; IANNUZZI, R.; QUING-ZHU YIN. 2018. A new stratigraphic framework built on U-Pb single-zircon TIMS ages and implications for the timing of the penultimate icehouse (Paraná Basin, Brazil). Geological Society of America Bulletin, 130(5-6): 848858. https://doi.org/10.1130/B31775.1

GRIFFIS, N.P.; MONTAÑEZ, I.P.; FEDORCHUK, N.; ISBELL, J.; MUNDIL, R.; VESELY, F.; WEINSHULTZ, L.; IANNUZZI, R.; GULBRANSON, E.; TABOADA, A.; PAGANI, A.; SANBORN, M.E.; HUYSKENS, M.; WIMPENNY, J.; LINOL, B.; YIN, Q. 2019. Isotopes to ice: Constraining provenance of glacial deposits and ice centers in west-central Gondwana. Palaeogeography, Palaeoclimatology, Palaeoecology, 531 (Part B): 108745. https:// doi.org/10.1016/j.palaeo.2018.04.020.

HOLZ, M.; FRANÇA, A.B.; SOUZA, P.A.; IANNUZZI, R.; ROHN, R. 2010. A stratigraphic chart of the Late Carboniferous/ Permian succession of the eastern border of the Paraná Basin, Brazil, South America. Journal of South American Earth Sciences, 29, 381-399. https://doi.org/10.1016/j.jsames.2009.04.004

ISBELL, J.L.; HENRY, L.C.; GULBRANSON, E.L.; LIMARINO, C.O.; FRAISER, M.L.; KOCH, Z.J.; CICCIOLI, P.L.; DINEEN,
A.A. 2012. Glacial paradoxes during the late Paleozoic ice age: Evaluating the equilibrium line altitude as a control on glaciation. Gondwana Research, 22: 1-19. https://doi. org/10.1016/j.gr.2011.11.005

LEONARDOS, O.H. 1938. Varvitos de Itu. Mineração e Metalurgia, 12: 221-233.

LERMEN, R. 2006. Assinaturas icnológicas em depósitos glaciogênicos do Grupo Itararé no $R S$. São Leopoldo, UNISINOS, Dissertação de Mestrado, $84 \mathrm{p}$.

LIMARINO, C.O.; CÉSARI, S.N.; SPALLETI, L.A.; TABOADA, A.C.; ISBELL, J.L.; GEUNA, S.; GULBRANSON, E.L. 2014. A paleoclimatic review of southern South America during the late Paleozoic: A record from icehouse to extreme greenhouse conditions. Gondwana Research, 25: 13961421. https://doi.org/10.1016/j.gr.2012.12.022

LONGHIM, M.E.; SOUZA, P.A.; ROHN, R. 2002. Palinologia do Grupo Itararé na região de Salto (Carbonífero Superior), Estado de São Paulo, Brasil. Parte 1 - Palinologia sistemática. Revista Universidade Guarulhos, Geociências, VII(6): 43-60.

LÓPEZ-GAMUNDÍ, O.R.; BUATOIS, L.A. 2010. Introduction: Late Paleozoic glacial events and postglacial transgressions in Gondwana. The Geological Society of America, Special Paper, 468: v-viii. https://doi.org/10.1130/SPE468

MENDES, J.C. 1944. A geologia dos arredores de Itu. Boletim da Associação dos Geógrafos Brasileiros, 4: 31-40.

MEZZALIRA, S. 1969. Geologia de subsuperfície em Itu, SP. Ocorrência de "roche moutonnée" nos testemunhos de sondagem. Anais Academia Brasileira de Ciências, 4(1): 83-89.

MILANI, E.J. 1997. Evolução tectono-estratigráfica da Bacia do Paraná e seu relacionamento com a geodinâmica fanerozoica do Gondwana Sul-Ocidental. Instituto de Geociências, Universidade Federal do Rio Grande do Sul, Porto Alegre, Tese de Doutorado, 2 vols.

MILANI, E.J.; RAMOS, V.A. 1998. Orogenias paleozoicas no domínio sul-ocidental do Gondwana e os ciclos de subsidência da Bacia 
do Paraná. Revista Brasileira de Geociências, 28: 473-484.

MILANI E.J.; RANGEL H.D.; BUENO G.V.; STICA J.M.; WINTER W.R.; CAIXETA J.M.; PESSOA NETO O.C. 2007. Bacias sedimentares brasileiras: Cartas estratigráficas - Introdução. Boletim de Geociências da Petrobras, 15(2):183-198.

MODENESI, M.C. 1974a. Níveis de erosão e formações superficiais na região de Itu-Salto, SP. Revista Brasileira de Geociências, 4(4): 228-246.

MODENESI, M.C. 1974b. Contribuição à geomorfologia da região de Itu-Salto: estudo de formações superficiais. IGEOG-USP, São Paulo, 100 p. (Série Teses e Monografias, 10).

MOTTIN, T.E.; VESELY, F.F.; RODRIGUES, M.C.N.L.; KIPPER, F.; SOUZA, P.A. 2018. The paths and timing of late Paleozoic ice revisited: New stratigraphic and paleo-ice flow interpretations from a glacial succession in the upper Itararé Group (Paraná Basin, Brazil). Palaeogeography, Palaeoclimatology, Palaeoecology, 490: 488-504. https://doi. org/10.1016/j.palaeo.2017.11.031

NEVES, M.A. 2005. Análise integrada aplicada à exploração de água subterrânea na Bacia do Rio Jundiai (SP). Instituto de Geociências e Ciências Exatas - IGCE, Campus de Rio Claro, Universidade Estadual Paulista, Tese de Doutorado, $200 \mathrm{p}$.

ODA, G.H. 1998. Contribuição à hidrogeologia da Região entre Salto e Pirapora de Itu $(S P)$ : análise da produtividade, ocorrência e circulação das águas subterrâneas dos sistemas aqüiferos Tubarão e Cristalino. Instituto de Geociências, Universidade de São Paulo, São Paulo, Dissertação de Mestrado, 100 p.

ODA， G.H.; TAKEUCHI， D.M.; EZAKI， S.; IRITANI, M.A.; VARNIER, C.; PENTEADO, D.R.; LIMA, C.V.F.; SILVA, A.H.; ZUCA, N.L.; PACHECO, R.P. 2012. Geometria do Aquífero Tubarão entre os municípios de Indaiatuba e Capivari (SP). Revista do Instituto Geológico, 33(1): 23-40. http://www. doi.org/10.5935/0100-929X.20120002
PÉREZ-AGUILAR, A.; PETRI, S.; HYPÓLITO, R.; EZAKI, S.; SOUZA, P.A.; JULIANI, C.; MONTEIRO, L.V.S.; MOSCHINI, F. 2009. Superfícies estriadas no embasamento granítico e vestígio de pavimento de clastos neopaleozóicos na região de Salto, SP. Revista da Escola de Minas, 62(1): 17-22. https://doi. org/10.1590/S0370-44672009000100004

PETRI, S. 1986. Notas adicionais sobre os ritmitos de Itu, Paleozóico Superior da Bacia do Paraná, São Paulo. Revista do Instituto Geológico, 7(1/2): 31-34.

PONÇANO, W.L.; CARNEIRO, C.D.R.; BISTRICHI, C.A.; ALMEIDA, F.F.M.; PRANDINI, F.L. 1981. Mapa geomorfológico do Estado de São Paulo. IPT, Monografias 5, Publicação IPT 1183, vol. 1, 94 p.

ROCHA-CAMPOS, A.C. 1967. The Tubarão Group in the Brazilian portion of the Paraná Basin. In: J.J. Bigarella, R.D. Becker, I.D. Pinto (Eds.), Problems in Brazilian Gondwana Geology, Curitiba, p. 27-102.

ROCHA-CAMPOS, A.C. 2002a. Rocha moutonnée de Salto, SP. In: C. Schobbenhaus, D.A. Campos, E.T. Queiroz, M. Winge, M. Berbert-Born (Eds.), Sítios Geológicos e Paleontológicos do Brasil, DNPM/CPRM, $1^{\text {a }}$ ed., Brasília, Comissão Brasileira de Sítios Geológicos e Paleobiológicos (SIGEP), v. 1, p. 55-159.

ROCHA-CAMPOS, A.C. 2002b. Varvito de Itu, SP Registro clássico da glaciação neopaleozoica. In: C. Schobbenhaus, D.A. Campos, E.T. Queiroz, M. Winge, M. Berbert-Born (Eds.), Sítios Geológicos e Paleontológicos do Brasil, DNPM/CPRM, $1^{\text {a }}$ ed., Brasília, Comissão Brasileira de Sítios Geológicos e Paleobiológicos (SIGEP), v. 1, p. 147-154.

ROCHA-CAMPOS, A.C.; DOS SANTOS, P.R.; CANUTO, J.R. 2008. Late Paleozoic glacial deposits of Brazil: Paraná Basin. In: C.R. Fielding, T.D. Frank, J.L. Isbell (Eds.), Resolving the Late Paleozoic Age in Time and Space: Geological Society of America Special Paper, 441, pp. 97-114. https://doi. org/10.1130/2008.2441(07)

ROCHA-CAMPOS, A.C.; BASEI, M.A.S.; NUTMAN, A.P.; SANTOS, P.R.; 
PASSARELLI, C.R.; CANILE, F.M.; ROSA, O.C.R.; FERNANDES, M.T.; SANTA ANA, H.; VEROSLAVSKY, G. 2019. U-Pb Zircon Dating of Ash Fall Deposits from the Paleozoic Paraná Basin of Brazil and Uruguay: A Reevaluation of the Stratigraphic Correlations. The Journal of Geology, 127: 167-182. https://doi.org/10.1086/701254

ROSA, E.L.M.; VESELY, F.F.; FRANÇA, A.B. 2016. A review on late Paleozoic ice-related erosional landforms in the Paraná Basin: origin and paleogeographical implications. Brazilian Journal of Geology, 46(2): 147-166. https:// doi.org/10.1590/2317-4889201620160050

SALVETTI, R.A.P. 2005. Sistemas deposicionais e paleogeografia do Subgrupo Itararé (Neopaleozoico da Bacia do Paraná), na região entre Itu e Indaiatuba, SP. Instituto de Geociências, Universidade de São Paulo, Dissertação de Mestrado, 110 p.

SANTOS, P.R.; ROCHA-CAMPOS, A.C.; CANUTO, J.R. 1996. Patterns of late Palaeozoic deglaciation in the Paraná Basin, Brazil. Palaeogeography, Palaeoclimatology, Palaeoecology, 125: 165-184. https://doi. org/10.1016/S0031-0182(96)00029-6

SCHNEIDER, R.L.; MUHLMANN, H.;TOMMASI, E.; MEDEIROS, R.A.; DAEMON, R.F.; NOGUEIRA, A.A. 1974. Revisão estratigráfica da Bacia do Paraná. In: SBG, CONGRESSO BRASILEIRO DE GEOLOGIA, 28, Porto Alegre, Anais, 1: 41-65.

SOUZA, P.A. 2006. Late Carboniferous palynostratigraphy of the Itararé Subgroup, northeastern Paraná Basin, Brazil. Review of Palaeobotany and Palynology, 138(1): 9-29. https://doi.org/10.1016/j. revpalbo.2005.09.004

SOUZA, P.A.; MARQUES-TOIGO, M. 2005. Progress on the palynostratigraphy of the Permian strata of the Rio Grande do Sul State, Paraná basin, Brazil. Anais da Academia Brasileira de Ciências, 77(2): 353-365. http://dx.doi.org/10.1590/S000137652005000200012

SOUZA, P.A.; FÉLIX, C.M.; PÉREZ-AGUILAR, A.; PETRI, S. 2010. Pennsylvanian palynofloras from the Itu rhythmites (Itararé
Subgroup, Paraná Basin) in São Paulo State, Brazil. Revue de Micropaléontologie, 53(2): 69-83. https://doi.org/10.1016/j. revmic.2008.10.003

TASSI, L.V. 2010 Estudo tafonômico de icnofósseis atribuíveis à diplópodos (Myriapoda) no Parque Municipal do Varvito, Município de Itu (São Paulo, Brasil). Instituto de Ciências Biológicas, Universidade Federal de Juiz de Fora, Juiz de Fora, Dissertação de Mestrado, $75 \mathrm{p}$.

TEIXEIRA,A.L.; BOGGIANI, P.C.; FERNANDES, A.J.; MASSOLI, M.; TORRES, C.C.; VIEIRA, P.C. 1991. Mapa Geológico do Município de Itu (Anexo 2.1) e Mapa de Pontos de Descrições Geológicas e Geomorfológicas (Anexo 2.2). In: Instituto Geológico, Subsídios do Meio Físico Geológico ao Planejamento do Município de Itu (SP), São Paulo, 3 volumes (Relatório Técnico do Instituto Geológico).

VESELY, F.F.; ASSINE, M.L. 2004. Seqüências e tratos de sistemas deposicionais do Grupo Itararé, Norte do Estado do Paraná. Revista Brasileira de Geociências, 34 (2): 219-230. https://doi.org/10.25249/03757536.2004342219230

VESELY, F. F.; ASSINE, M.L. 2006. Deglaciation sequences in the Permo-Carboniferous Itararé Group, Paraná Basin, southern Brazil. Journal of South American Earth Sciences, 22(3-4): 156-168. https://doi.org/10.1016/j. jsames.2006.09.006

VESELY, F.F.; TRZASKOS, B.; KIPPER, F.; ASSINE, M.L.; SOUZA, P.A. 2015. Sedimentary record of a fluctuating ice margin from the Pennsylvanian of western Gondwana: Paraná Basin, southern Brazil. Sedimentary Geology, 326: 45-63. https://doi. org/10.1016/j.sedgeo.2015.06.012

VIVIANI, J.B.; ROCHA-CAMPOS, A.C. 2002. Late Paleozoic exhumed glacial erosive landscape in Salto, SP. Anais da Academia Brasileira de Ciências, 74(3), 549-550. http://dx.doi. org/10.1590/S0001-37652002000300034 
Endereço dos autores:

Setembrino Petri, Artur Chahud e Ana Maria Góes - Instituto de Geociências, Departamento de Geologia Sedimentar e Ambiental, Universidade de São Paulo, Rua do Lago, 562, Cidade Universitária, CEP 05508900, São Paulo, SP, Brasil.E-mail: spetri@usp.br, arturchahud@yahoo.com, anamgoes@gmail.com

Annabel Perez-Aguilar (In Memoriam), Sibele Ezaki, Silvio Takashi Hiruma - Instituto Geológico, Secretaria do Meio Ambiente e Infraestrutura, Rua Joaquim Távora, 822, CEP 04015-011, São Paulo, SP, Brasil.E-mails: sibezaki@sp.gov.br, shiruma@sp.gov.br

Paulo Alves de Souza - Instituto de Geociências, Departamento de Paleontologia e Estratigrafia, Universidade Federal do Rio Grande do Sul, Av. Bento Gonçalves, 9500, Campus do Vale, CEP 91540000, Porto Alegre, RS, Brasil.E-mail: paulo.alves.souza@ufrgs.br

Artigo submetido em 14 de fevereiro de 2019, aceito em 29 de dezembro de 2019. 